\title{
Blends of Reactive Diluents with Phenylethynyl-Terminated Arylene Ether Oligomers
}

Rachel Louise Knudsen

College of William \& Mary - Arts \& Sciences

Follow this and additional works at: https://scholarworks.wm.edu/etd

Part of the Organic Chemistry Commons

\section{Recommended Citation}

Knudsen, Rachel Louise, "Blends of Reactive Diluents with Phenylethynyl-Terminated Arylene Ether Oligomers" (1995). Dissertations, Theses, and Masters Projects. Paper 1539625959.

https://dx.doi.org/doi:10.21220/s2-76tg-pf82

This Thesis is brought to you for free and open access by the Theses, Dissertations, \& Master Projects at W\&M ScholarWorks. It has been accepted for inclusion in Dissertations, Theses, and Masters Projects by an authorized administrator of W\&M ScholarWorks. For more information, please contact scholarworks@wm.edu. 


\title{
BLENDS OF REACTIVE DILUENTS WITH PHENYLETHYNYL- TERMINATED ARYLENE ETHER OLIGOMERS
}

\author{
A Thesis \\ Presented to
}

The Faculty of the Applied Science Department The College of William and Mary in Virginia

\author{
In Partial Fulfillment \\ of the Requirements for the Degree of \\ Master of Arts
}

by

Rachel L. Knudsen

1995 
APPROVAL SHEET

This thesis is submitted in partial fulfillment of the requirements for the degree of

Master of Arts

$\frac{\text { Rachel L Keen }}{\text { Rachel I. Knudsen }}$

Approved, July 1995

$\frac{\text { Marl Sunder }}{\text { Mark Hinders }}$
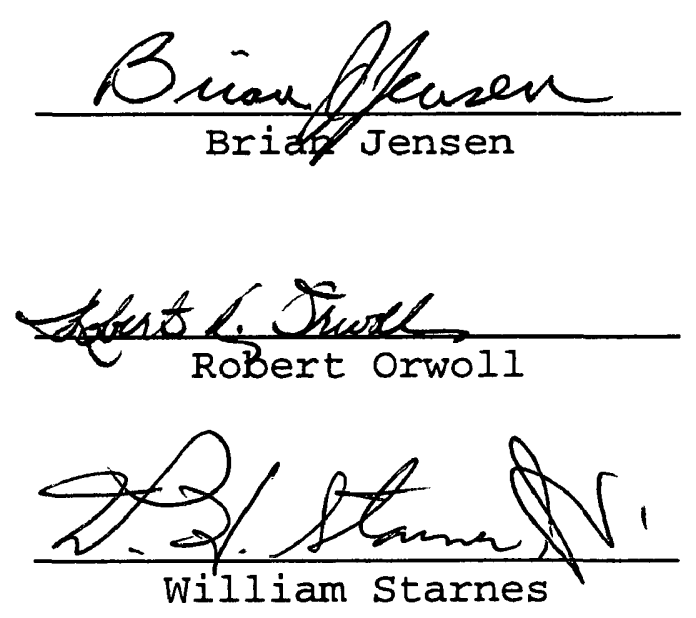

ii 
Acknowledgements. . . . . . . . . . . . . . . . . . . . . iv List of Tables. . . . . . . . . . . . . . . . . . . . . . . v List of Figures . . . . . . . . . . . . . . . . . . . vi Abstract. . . . . . . . . . . . . . . . . . . . . vii

Introduction. . . . . . . . . . . . . . . . . . . . . . 2

Background . . . . . . . . . . . . . . . . . . 2

Poly (arylene ether)s . . . . . . . . . . . . . . 3

Acetylene Terminated Prepolymers . . . . . . . . . .4

Acetylene Coreactants. . . . . . . . . . . . . . 6

objective. . . . . . . . . . . . . . . . . . 6

Experimental. . . . . . . . . . . . . . . . . . . . . . . . . . 9

Starting Materials . . . . . . . . . . . . . . . . . . . . . . .

Synthetic Routes . . . . . . . . . . . . . . . . . . . . . . . . . .

Diluent Synthesis. . . . . . . . . . . . 9

oligomer Synthesis. . . . . . . . . . . . 11

Blends. . . . . . . . . . . . . . . . . 12

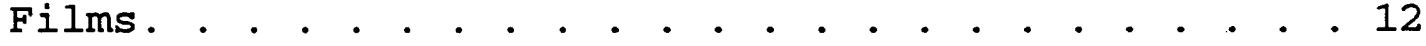

Characterization . . . . . . . . . . . . . . 13

Elemental Analysis. . . . . . . . . . . 13

Melting Points. . . . . . . . . . . . . . 13

Molecular Weight Determination. . . . . . . . 13

Glass Transition Temperatures . . . . . . . . 14

Solvent Resistance. . . . . . . . . . . . 14

Tensile Properties. . . . . . . . . . . . 15

Rheology. . . . . . . . . . . . . . . . 15

Adhesive Specimens. . . . . . . . . . . 16

Results and Discussion. . . . . . . . . . . . 18

Synthetic Routes . . . . . . . . . . . . . . 18

Blends . . . . . . . . . . . . . . . . . . . . . . . 18

Films. . . . . . . . . . . . . . . . . . . . . . . 19

Molecular Weight Determination . . . . . . . . . 20

Characterization . . . . . . . . . . . . . . . . 21

Solvent Resistance. . . . . . . . . . . . . 22

Glass Transition Temperatures . . . . . . . 24

Tensile Properties. . . . . . . . . . . . 26

Rheology. . . . . . . . . . . . . . . 30

Adhesive Specimens. . . . . . . . . . . 33

Conclusions . . . . . . . . . . . . . . . . . . . . 39

Appendix. . . . . . . . . . . . . . . . . . . . 73

Notes . . . . . . . . . . . . . . . . . . . . . . . 75

Bibliography. . . . . . . . . . . . . . . . . . . . . . 78 


\section{ACKNOWLEDGEMENTS}

The writer wishes to express her appreciation to Dr. Brian J. Jensen for his support, guidance, and insight throughout this investigation. The author is also indebted to Professor Robert Orwoll for his advice throughout this degree program and to he and Professors William Starnes and Mark Hinders for their careful reading of this manuscript and their suggestions and comments.

The author also acknowledges the assistance of Mia Siochi for performing gel permeation chromatography, Tan Hou for collecting the rheological data, Hoa luong for preparing the adhesive specimens, and Fred Whitehead for performing tensile and lap shear tests.

To the Graduate Student Researchers Program and the Composites and Polymers Branch at NASA Langley Research Center, the author is grateful for the financial support and the guidance received. 


\section{List of Tables}

Table

Page

I Summary of Molecular Weight Results. . . . . . . . . . . . . . . . . . 42

II Resistance of Cured Films to Jet Fuel. . . . . . . . . . . . . . . . . . 43

III Resistance of Cured Films to Hydraulic Fluid. . . . . . . . . . . . . . 44

IV Resistance of Cured Films to

$\mathrm{V}$ Resistance of Cured Films to Methyl Ethyl Ketone. . . . . . . . . . 46

VI Glass Transition Temperatures of Cured Films. . . . . . . . . . . . . . . 47

VII Tensile Modulus of Films at Room Temperature. . . . . . . . . . . . 48

VIII Tensile strength of Films at Room Temperature. . . . . . . . . . . . . 49

IX Percent Strain of Films at Room Temperature. . . . . . . . . . . . 50

$x$ Tensile Modulus of Films at Elevated Temperature. . . . . . . . . . 51

XI Tensile strength of Films at Elevated Temperature. . . . . . . . . . 52

XII Percent strain of Films at Elevated Temperature. . . . . . . . . 53

XIII Minimum Melt Viscosity and Gel Time. . . . . . . . . . . . . . . . . . . . 54

XIV Ti/Ti Tensile Shear strengths and Processing Conditions . . . . . . . . 55

XV Ti/Ti Tensile Shear Strengths. . . . . . . . . 56 


\section{List of Figures}

Figure

Page

I Strength and Elongation vs.

Degree of Crosslinking. . . . . . . . . . . 57

II Synthesis of PE-A. . . . . . . . . . . . . . . . 58

III Synthesis of PE-B. . . . . . . . . . . . . . . 59

IV Synthesis of PE-C. . . . . . . . . . . . . . . . . 60

$\mathrm{V}$ Synthesis of PE-D. . . . . . . . . . . . . . . . . . 61

VI Synthesis of PE-E. . . . . . . . . . . . . . . . 62

VII Synthesis of PETAEs. . . . . . . . . . . . . . . 63

VIII DSC of Incompletely Cured

10D-80/20 Film. . . . . . . . . . . . 64

IX DSC of Completely Cured

10D-80/20 Film. . . . . . . . . . . . 65

$\mathrm{x}$ Stress-Strain Curves of Five

Types of Polymeric Materials. . . . . . . . 66

XI DSC of 10B-80/20 Powder. . . . . . . . . . . . . . . 67

XII DSC of 10A-80/20 Powder. . . . . . . . . . . . . . . 68

XIII Rheology Plot of 80/20 Copolymer . . . . . . . . . . 69

XIV Rheology Plot of 10A-80/20 Blend . . . . . . . . . . 70

XV Rheology Plot of 20A-80/20 Blend . . . . . . . . . . 71

XVI Rheology Plot of 10E-80/20. Blend . . . . . . . . . . 72 


\section{ABSTRACT}

The purpose of this study is to improve the physical properties of phenylethynyl terminated poly(arylene ether) (PETAE) oligomers while decreasing the melt viscosity to improve processability. The approach is to blend phenylethynyl containing reactive diluents with PETAE oligomers. The diluents plasticize the oligomers during processing but become incorporated into the network when the blend is cured.

Five diluents were synthesized and blended with each of three PETAE oligomer backbones at two diluent/oligomer ratios, giving a total of thirty blends and three non-blended oligomer controls. Experiments were performed to test solvent resistance, glass transition temperature, tensile strength and modulus, melt viscosity, and $\mathrm{Ti} / \mathrm{Ti}$ tensile shear strength. Two blends were selected which best met the goals of the research. These blends, $10 \mathrm{~A}-80 / 20$ and $20 \mathrm{~A}-80 / 20$, contained the same diluent and backbone but different diluent/oligomer ratios.

Cured films of the selected blends either did not swell at all or swelled less than the control in the solvents tested. The glass transition temperatures of the cured blends increased by 15 to $16^{\circ} \mathrm{C}$ as compared to the control.

The cured film of $10 \mathrm{~A}-80 / 20$ showed an increase of $34 \%$ in tensile strength and $16 \%$ in tensile modulus at room temperature as compared to the non-blended oligomer control. Films of the two selected blends showed an increase in tensile properties at $177^{\circ} \mathrm{C}$, with a strength increase as high as $47 \%$ over the control and a modulus increase up to $14 \%$. The minimum melt viscosities of both blends decreased as compared to the controls, and the viscosity of one blend, 20A-80/20, was a factor of ten lower than the control.

The $\mathrm{Ti} / \mathrm{Ti}$ tensile shear strengths of both selected blends were higher than those of the control in all test conditions. Improvements of 40 and $31 \%$ were seen at room temperature and $177^{\circ} \mathrm{C}$, respectively, and improvements of 22 to $84 \%$ were seen in the room temperature test following a $48 \mathrm{~h}$ soak in one of several solvents.

The results suggest that an increase in crosslink density occurs from the addition of the diluents, and improved properties are being attained because of this increase. 


\section{BLENDS OF REACTIVE DILUENTS WITH}

\section{PHENYLETHYNYL-TERMINATED ARYLENE ETHER}

\section{OLIGOMERS}




\section{Introduction}

\section{Background:}

Aircraft companies from several nations are currently conducting research toward the next level of competition in the aviation industry, the "long range, economical, environmentally acceptable, second generation supersonic passenger transport."1 In order to increase the competitiveness of American industry in this area, the National Aeronautics and Space Administration (NASA) is conducting a High Speed Research (HSR) program involving government and industry in the development of the necessary technology for the High speed Civil Transport, or HSCT.

Among the critical technologies being developed are high performance polymeric materials for use as adhesives and composite matrices in structural components. These materials must withstand a temperature of $177^{\circ} \mathrm{C}\left(350^{\circ} \mathrm{F}\right)$ for 60,000 hours while maintaining desirable mechanical properties. ${ }^{2}$ Additionally, these materials must be able to be processed easily and inexpensively in order to provide cost-effective aircraft components. One method of manufacturing fiber- 
reinforced composite parts, resin transfer molding (RTM), involves the injection of a liquid resin into a mold containing the fiber. RTM can be used with a preform that already has the shape of the desired product, thus allowing complicated shapes to be formed without the need for fasteners. ${ }^{3}$ Current RTM technology, however, requires the injected resin to be of low viscosity, about 10 poise. Current engineering thermoplastics have melt viscosities that are too high, and low melt viscosity thermosets are often brittle after cure. Thus, no current materials technology exists with the proper combination of mechanical properties and thermal stability that would allow RTM to be used to manufacture composite parts for use in the HSCT.

\section{Poly(arylene ether)s:}

High molecular weight poly(arylene ether) (PAE) thermoplastics which do not contain crosslinks or crystallinity exhibit an attractive combination of low cost, processability, and mechanical properties. ${ }^{4-7}$ When exposed to polar solvents, however, they undergo crazing and cracking or dissolve. This makes them unsuitable for use in structural aerospace applications, due to the exposure of airplanes to solvents such as jet fuel, hydraulic fluid, paint strippers, and deicing fluid. ${ }^{8}$ One approach to improving the solvent resistance is to use semicrystalline materials such as in poly(ether ether ketone) (PEEK). ${ }^{9}$ However, this approach 
requires high molding temperatures and gives poor hightemperature mechanical properties. ${ }^{6}$ Another method to improve solvent resistance is the introduction of functional groups, either at the ends of or pendent along the polymer chain, which can be thermally cured to form crosslinks and chain extensions. These functional groups include nadimide, ${ }^{10}$ cyanato, ${ }^{11}$ and acetylene ${ }^{12,13}$ groups.

\section{Acetylene Terminated Prepolymers:}

oligomers and polymers containing the acetylenic (ethynyl) group $(-\mathrm{C} \equiv \mathrm{C}-\mathrm{H})$ and substituted acetylenic groups, particularly phenylethynyl $\left(-\mathrm{C} \equiv \mathrm{C}-\mathrm{C}_{6} \mathrm{H}_{5}\right)$, have received considerable attention. ${ }^{13}$ oligomers and polymers containing acetylenic groups have excellent shelf lives and relatively low melt viscosities, and they thermally cure without the evolution of volatiles. The cured resins generally have improved solvent resistance, moisture resistance, and mechanical properties as compared to the analogous thermoplastic polymers. These materials have been used as films, coatings, adhesives, and composite matrices.

Several poly(arylene ether) backbones have been modified with ethyny $1^{14-17}$ and phenylethyny $1^{16-19}$ groups. Over the past few years, several phenylethynyl terminated arylene ether (PETAE) oligomers with attractive properties have been developed. ${ }^{20-22}$ 
A model compound study by Bryant, Jensen, and Hergenrother at NASA Langley Research Center ${ }^{20}$ indicated that these oligomers should display excellent melt stability at $200^{\circ} \mathrm{C}$ and cure in one hour at $350^{\circ} \mathrm{C}$. This is beneficial for processing, as the oligomers can be processed in the melt without gelation. The structure of the cured form of the phenylethynyl group is currently unknown, but it is believed that a combination of chain extension, branching, and cross-linking is occurring.

As part of the same study, PETAE oligomers were synthesized with theoretical number average molecular weights $\left(\mathrm{M}_{n} \mathrm{~S}\right)$ of 3000 and $6000 \mathrm{~g} / \mathrm{mol}$. The cured $6000 \mathrm{~g} / \mathrm{mol}$ oligomers exhibited higher glass transition temperatures $\left(\mathrm{T}_{\mathrm{g}} \mathrm{S}\right)$ and higher $\mathrm{Ti} / \mathrm{Ti}$ tensile shear strengths than the corresponding $3000 \mathrm{~g} / \mathrm{mol}$ oligomers. The system cured from a $6000 \mathrm{~g} / \mathrm{mol}$ PETAE oligomer synthesized from 9,9-bis(4-hydroxyphenyl)fluorene (BPF) and 4,4'-difluorobenzophenone (DFB) had the highest tensile shear strengths $\left(4320 \mathrm{psi}\right.$ at $23^{\circ} \mathrm{C}$ and $4030 \mathrm{psi}$ at $\left.177^{\circ} \mathrm{C}\right)$ of the twelve systems in the study as well as the highest $T_{g}\left(263^{\circ} \mathrm{C}\right)$.

In order to improve solvent resistance of the cured BPF/DFB oligomers, a second study performed at NASA Langley by Jensen and Bryant ${ }^{21}$ focused on the synthesis and characterization of PETAE oligomers from DFB and various amounts of BPF and 4,4'- 
biphenol (BP). Solvent resistance was improved with the addition of biphenol units, but the $\mathrm{Tg}$ and $\mathrm{Ti} / \mathrm{Ti}$ tensile shear strengths decreased.

\section{Acetylene Coreactants:}

In a study performed by Jensen at NASA Langley in 1991, ethynyl terminated polysulfones (ETPS) at three different $\mathrm{M}_{\mathrm{n}} \mathrm{S}$ were blended with 10 and 20 wt of of a low molecular weight diethynyl terminated compound. ${ }^{23}$ With curing, the compound was incorporated into the polymer network, increasing the final crosslink density as compared to the ETPS with no coreactant.

The Tg of the cured ETPS with the lowest $\mathrm{M}_{\mathrm{n}}(2906 \mathrm{~g} / \mathrm{mol})$ increased significantly $\left(8\right.$ to $\left.13^{\circ} \mathrm{C}\right)$ after addition of the coreactant. The $\mathrm{T}_{\mathrm{g}} \mathrm{s}$ of the cured $5616 \mathrm{~g} / \mathrm{mol}$ and $9146 \mathrm{~g} / \mathrm{mol}$ blended systems increased by 0 to $2^{\circ} \mathrm{C}$. Toughness of cured moldings was determined to be inversely proportional to ethynyl group content. The moldings were tougher than epoxies but not as tough as high molecular weight polysulfone.

\section{Objective:}

The objective of this work has been to modify further the biphenol-containing PETAE oligomers in order to improve solvent resistance, increase modulus and adhesive strength, and reduce melt viscosity. The approach is to blend five 
different phenylethynyl-containing diluents with three PETAE oligomers, similar to the aforementioned study of ETPS with an ethynyl compound. However, the phenylethynyl group begins to cure about $100^{\circ} \mathrm{C}$ higher than the ethynyl group. This should increase the likelihood that the phenylethynyl compounds melt and become incorporated into the PETAE oligomers before the reaction of the endgroups begins to take place. In addition, the diluents should reduce the melt viscosity during processing and increase the crosslink density after cure. Since glass transition temperature, modulus, and solvent resistance generally increase with increased crosslink density, improvements are expected in physical, mechanical, and processing properties of the oligomer/diluent blends as compared to the PETAE oligomers alone.

In rubbers, the variation in tensile strength with degree of crosslinking goes through a pronounced maximum at a low degree of crosslinking and then rapidly decreases as the crosslinking increases. If a similar pattern exists for these materials used below their $\mathrm{T}_{\mathrm{g}}$, the strength of the modified PETAEs could increase or decrease, depending on whether or not the critical degree of crosslinking is surpassed. The percent elongation to break decreases steadily as the degree of crosslinking increases. This is a result of the increased brittleness of a highly crosslinked system. Both of these 
effects are shown in Figure I. ${ }^{24}$ The amount of diluent used was varied in order to find the degree of crosslinking that gave the best overall properties.

In addition to improving properties, the addition of the diluent to the PETAE oligomers is expected to reduce the melt viscosity of the uncured system. This can happen in two ways. Above the $T_{g}$ of the uncured oligomers, the softened system can act as a solvent, dissolving the diluents. Alternatively, the diluents can melt and become incorporated into the system. In either case, the diluent plasticizes the oligomers during processing. A plasticizer acts as a lubricant, in which the small molecules push the polymer chains further apart, easing their movement. ${ }^{25}$ This lowers both the $\mathrm{T}_{\mathrm{g}}$ and the modulus. In this case, however, the diluent is incorporated into the polymer network upon cure. The decrease in $T_{g}$ and modulus is only seen during processing, which should translate to lower temperatures and pressures and therefore lower processing costs. If the melt viscosity is sufficiently lowered, RTM will be able to be used with these matrices in composite processing. 


\section{Experimental}

\section{Starting Materials:}

4,4'-Biphenol (BP, mp $278^{\circ} \mathrm{C}$, dec.), 9,9'-bis(4-hydroxyphenyl)fluorene (BPF, mp $215-217^{\circ} \mathrm{C}$ ), 4,4'-difluorobenzophenone (DFB, mp $106.5-108^{\circ} \mathrm{C}$ ) and 1,3,5-trihydroxybenzene (THB, mp $224^{\circ} \mathrm{C}$ ) were obtained commercially and recrystallized prior to use. The 4-fluoro-4'-phenylethynylbenzophenone (FPB) was prepared as previously reported ${ }^{20}$ by Daychem Laboratories, Inc. and used as received. 4-Phenylethynylphenol (PEP) was prepared in a similar manner to the 3-phenylethynylphenol previously reported. ${ }^{26}$

\section{Synthetic Routes:}

\section{Diluent Synthesis}

PE-A - In a three-necked round-bottom flask equipped with overhead stirring assembly, nitrogen inlet, Dean-Stark trap and reflux condenser were placed equimolar amounts (typically $0.1 \mathrm{~mol}$ ) of PEP and FPB, a $10 \%$ stoichiometric excess of pulverized $\mathrm{K}_{2} \mathrm{CO}_{3}, \mathrm{~N}, \mathrm{~N}$-dimethylacetamide (DMAC), and toluene to form a reactant mixture comprising 25 wt $\%$ solids. The reaction scheme is shown in Figure II. The solution was 
heated to reflux and the toluene and water were removed by azeotropic distillation. The reaction was held at $155-160^{\circ} \mathrm{C}$ for at least 16 hours, then cooled to room temperature and poured into acidic (5\% acetic acid) water. The precipitate was collected by filtration and washed with methanol. Recrystallization from toluene gave a pale yellow powder (52\% yield), $\mathrm{mp} 238-241^{\circ} \mathrm{C}$ (vis). The final product was dried in vacuo at $140^{\circ} \mathrm{C}$. Elemental analysis calculated for $\mathrm{C}_{35} \mathrm{H}_{22} \mathrm{O}_{2}$ : C, $88.58 ; \mathrm{H}, 4.67 ; 0,6.74$. Found: C, $87.83 ; \mathrm{H}, 4.73 ; 0,7.54$.

PE-B - This compound was similarly prepared using a 1:2 molar ratio of $\mathrm{BP}$ and $\mathrm{FPB}$. The reaction scheme is shown in Figure III. A fine yellow powder was produced without recrystallization ( $93 \%$ yield), mp $344^{\circ} \mathrm{C}$ (DSC peak). Elemental analysis calculated for $\mathrm{C}_{54} \mathrm{H}_{34} \mathrm{O}_{4}: \mathrm{C}, 86.84 ; \mathrm{H}, 4.59 ; 0,8.57$. Found: $\mathrm{C}, 86.34 ; \mathrm{H}, 4.68 ; 0,8.98$.

PE-C - This compound was similarly prepared using a 1:2 molar ratio of $\mathrm{DFB}$ and $\mathrm{PEP}$. The reaction scheme is shown in Figure IV. Recrystallization from toluene gave an ivory colored powder (62\% yield), $\mathrm{mp} 249-256^{\circ} \mathrm{C}$ (vis). Elemental analysis calculated for $\mathrm{C}_{41} \mathrm{H}_{26} \mathrm{O}_{3}: \mathrm{C}, 86.90 ; \mathrm{H}, 4.62 ; 0,8.47$. Found: C, $85.71 ; H, 4.64 ; 0,9.65$.

PE-D - This compound was similarly prepared using a 1:2 molar 
ratio of $\mathrm{BPF}$ and $\mathrm{FPB}$. The reaction scheme is shown in Figure V. Recrystallization from 50/50 toluene/ethanol mixture gave a pale yellowish powder (83\% yield), mp $190-196^{\circ} \mathrm{C}$ (vis). Elemental analysis calculated for $\mathrm{C}_{67} \mathrm{H}_{42} \mathrm{O}_{4}: \mathrm{C}, 88.33 ; \mathrm{H}, 4.65$; $0,7.02$. Found: C, $87.74 ; \mathrm{H}, 4.76 ; 0,7.50$.

RE-E - This compound was similarly prepared using a 1:3 molar ratio of $T H B$ and FPB. The reaction scheme is shown in Figure VI. Recrystallization from toluene gave a light yellowish brown powder $\left(65 \%\right.$ yield), mp $233-238^{\circ} \mathrm{C}$ (vis). Elemental analysis calculated for $\mathrm{C}_{69} \mathrm{H}_{42} \mathrm{O}_{6}: \mathrm{C}, 85.70 ; \mathrm{H}, 4.38 ; 0,9.93$. Found: C, $84.98 ; \mathrm{H}, 4.27 ; 0,10.75$.

\section{Oligomer Synthesis}

Phenylethynyl-terminated arylene ether (PETAE) oligomers were prepared at $6000 \mathrm{~g} / \mathrm{mol}$ as previously reported. ${ }^{21}$ The modified Carothers equation was used to determine the offset of the monomers and the amount of FPB used to endcap the oligomers. A sample calculation is given in the Appendix, Calculation I. Oligomers were prepared from DFB with 100, 90, or 80 mol $\%$ BPF and 0,10 , or $20 \mathrm{~mol} \% \mathrm{BP}$, respectively. Despite the added solvent resistance of the backbones with higher than 20 percent BP content, it was determined that the $\mathrm{T}_{\mathrm{g}} \mathrm{s}$ of those materials were too low for them to be considered. The reaction scheme is shown in Figure VII. Oligomers will be referenced 
by the ratio of $\mathrm{BPF}$ to $\mathrm{BP}$, that is, $100 / 0,90 / 10$, and $80 / 20$.

\section{Blends}

Mixtures containing 10 and 20 wt $\%$ of each diluent with each oligomer were blended as dry powders for at least four hours using a ball mill, which produced a visually uniform mixture.

\section{Films:}

Solutions of oligomers and oligomer/diluent blends at 20 wt 8 solids in m-cresol were cast at $18 \mathrm{mils}$ (0.018 in.) thickness with a doctor's blade onto plate glass. The films were dried for two days at room temperature in a dry box. At this point, residual m-cresol remained in the films. The films were then cured at $350^{\circ} \mathrm{C}$ for at least one hour in a forced air oven. The method of drying to tack-free before curing was not used because it gave a brittle film that cracked and peeled away from the glass. The residual m-cresol served to plasticize the brittle prepolymer until the reaction of the phenylethynyl groups increased the toughness. Films were removed from the glass plate by lifting a corner with a razor blade, then soaking in water to complete removal. 


\section{Characterization:}

\section{Elemental Analysis}

Elemental analysis was performed on the diluents by Galbraith Laboratories, Inc., Knoxville, TN and Oneida Research Services, Inc., Whitesboro, NY.

\section{Melting Points}

Visual melting points were determined on a Thomas-Hoover melting point apparatus. Differential scanning calorimetry (DSC) melting points were performed on a Shimadzu DSC-50 calorimeter at a heating rate of $10^{\circ} \mathrm{C} / \mathrm{min}$. The melting point was taken at the peak of the melting endotherm.

\section{Molecular Weight Determination}

Gel permeation chromatography (GPC) was performed on the oligomers that were soluble in chloroform. Solutions were prepared by dissolving the powders in chloroform, and experiments were conducted after the samples were in solution overnight. Experiments were done at $35^{\circ} \mathrm{C}$ on a waters $150 \mathrm{C}$ GPC using a four-column bank consisting of $10^{3}, 10^{4}, 10^{5}$, and $10^{6}$ $\AA$ Styrage $1^{\mathrm{TM}}$ HT columns. The chromatograph was equipped with a differential refractive index detector connected in parallel to a Viscotek model 150R differential viscosity detector. The universal calibration curve was generated using Polymer Laboratories narrow molecular-weight-distribution polystyrene 
standards having the following molecular weights: 500, 870, $1340,1700,2450,2950,5970,7000,9200,11600,22000,30300$, $52000,66000,96000,156,000,220,000,500,800,1,030,000$, $1,750,000$, and $2,750,000 \mathrm{~g} / \mathrm{mol}$.

\section{Glass Transition Temperatures}

The glass transition temperatures $\left(T_{g} s\right)$ of the cured films were evaluated by DSC on a Shimadzu DSC-50 calorimeter at a heating rate of $20^{\circ} \mathrm{C} / \mathrm{min}$. The $\mathrm{T}_{\mathrm{g}}$ was taken at the inflection point of the heat flow vs. temperature curve.

\section{Solvent Resistance}

Solvent resistance of cured films was tested in toluene, methyl ethyl ketone (MEK), JP-5 jet fuel, and Chevron HyJet IV-A hydraulic fluid. A 0.50 in. by 0.20 in. rectangle cut from each cured film was allowed to soak in each solvent for 48 hours at room temperature. The length and width of the sample after soak was measured using digital calipers while the sample was still in the solvent, and the percent increase in area was calculated. To determine the precision to which the measurements could be made, a rectangle identical to those used in the experiment was measured before solvent exposure. Measurements in each direction were taken four times, and the $90 \%$ confidence interval was calculated. It was determined that the precision was about $\pm 2 \%$ of the area, so all films 
which swelled $2 \%$ or less were labeled as "no swelling" and films whose swelling was within $2 \%$ of one another were considered to be the same.

\section{Tensile Properties}

The thin film tensile properties were tested at room temperature and $177^{\circ} \mathrm{C}$ on a Sintech Model $2 \mathrm{~W}$ Screwdriven Test Machine according to ASTM standard D-882. Three or four replicate samples were used in each test and averages were reported with $90 \%$ confidence intervals. A sample calculation of a $90 \%$ confidence interval appears in the Appendix, Calculation II.

\section{Rheology}

The minimum viscosity of oligomers and blends was determined on a Rheometrics System 4 rheometer at $10 \mathrm{rad} / \mathrm{sec}$. The storage modulus, G', and the loss modulus, G", were plotted as a function of time. Two heating cycles were used. In the first, samples were heated from room temperature to $400^{\circ} \mathrm{C}$ at $4^{\circ} \mathrm{C}$ per minute. In the second, samples were heated from $100^{\circ} \mathrm{C}$ to $371^{\circ} \mathrm{C}$ at $4^{\circ} \mathrm{C}$ per minute and held at $371^{\circ}$ for at least 20 minutes. Data were collected for a minimum of 20 minutes after the gel point was reached. The gel point was taken at the first point above the $T_{g}$ where the storage modulus exceeded the loss modulus. The minimum viscosity in poise was 
taken as the minimum value of G" divided by the frequency, 10 $\mathrm{rad} / \mathrm{sec}$.

\section{Adhesive Specimens}

Warm NMP/prepolymer mixtures (15 wt 8 solids) of $80 / 20,10 \mathrm{~A}-$ $80 / 20$, and $20 \mathrm{~A}-80 / 20$ were used to coat 112 E-glass (A-1100 finish). Each coat was dried in a circulating air oven at $200^{\circ} \mathrm{C}$ for $1 \mathrm{~h}$. Several coats were used to provide a 10-14 mil thick tape. The final tape was dried at $225^{\circ} \mathrm{C}$ for $1 \mathrm{~h}$ to produce a low-volatile-content scrim cloth. Due to the low solubility of the blends, coating the scrim cloth was difficult, which resulted in variations in the thickness and poor quality. Also, because of the low molecular weight, the adhesive had a tendency to flake off the glass cloth before cure.

Titanium (Ti-6Al-4V) coupons, pretreated with Pasa-Jell $107^{\text {TM }}$ surface treatment, were bonded by heating to $371^{\circ} \mathrm{C}$, holding for 5,12 , and 15 minutes for $80 / 20,10 \mathrm{~A}-80 / 20$, and $20 \mathrm{~A}-80 / 20$, respectively, applying $15 \mathrm{psi}$, and holding under pressure to give a total hold of $1 \mathrm{~h}$ at $371^{\circ} \mathrm{C}$. The hold times were determined by the rheology data from the amount of time at $371^{\circ}$ required to reach a viscosity of 1000 poise. Four specimens of each resin were tested at $23^{\circ} \mathrm{C}$ and $177^{\circ} \mathrm{C}$. Two or three specimens of each resin were soaked for 48 hours at room 
temperature in either toluene, methyl ethyl ketone (MEK), JP-5 jet fuel, or Chevron HyJet IV-A hydraulic fluid and tested at $23^{\circ}$. All testing was done according to ASTM D-1002. As with tensile properties, average values and $90 \%$ confidence intervals are reported. 


\section{Results and Discussion}

\section{Synthetic Routes:}

The phenylethynyl-containing reactive diluents were synthesized in a single-step aromatic nucleophilic substitution reaction. Purification of the compounds was difficult, presumably due to the high molecular weights. The variations between the calculated and experimental elemental analysis values may be attributed to occluded impurities due to some precipitation occurring during the recrystallization process. The oligomers were synthesized at $6000 \mathrm{~g} / \mathrm{mol}$ according to calculations using the modified Carothers equation and end-capped with FPB.

\section{Blends:}

Blends of the diluents and polymers were prepared at both 10 and 20 wt $\%$ of the diluent. Five diluents and three oligomer backbones were used, providing a total of 30 blends. These, along with the three non-blended oligomers, were studied. The nomenclature used for the blends will consist of the weight percent diluent, the specific diluent used, and the backbone of the oligomer used. For example, $20 \mathrm{~A}-80 / 20$ refers to the 
blend of 20 wt 8 of the diluent PE-A with the oligomer which contains $80 \mathrm{~mol} \& \mathrm{BPF}$ and $20 \mathrm{~mol} \% \mathrm{BP}$. The non-blended oligomers will either be referred to as 100/0, 90/10, and $80 / 20$ or as controls, that is, $80 / 20$ is the control of any film made from a blend of a diluent and the 80/20 oligomer.

\section{Films:}

In order to cast films from the blends and the controls, a suitable solvent was needed. The average molecular weights of the blends were low due to addition of diluents. Therefore, a relatively high $20 \%$ solids content was used in order to achieve a viscous solution. The blends containing diluents $A$, $B$, and C were not completely soluble at $20 \%$ solids in all solvents tested, even when heated. The solvents tested included chloroform, 1-methyl-2-pyrrolidinone (NMP), $N, N-$ dimethylacetamide (DMAC), and m-cresol. m-Cresol was chosen because its higher viscosity allowed a film of uniform thickness to be cast from the clear solutions or uniform opaque mixtures. Also, since m-cresol has a high boiling point (i.e., low vapor pressure), it stayed in the film longer during heating than the other solvents. This plasticized the uncured film and prevented it from becoming brittle before the reaction of the phenylethynyl groups took place, which produced tough, creasable films.

Previous work by Bryant, Jensen, and Hergenrother ${ }^{20}$ showed that 
phenylethynyl-terminated oligomers could be cured completely at $350^{\circ} \mathrm{C}$ for one hour, based on the absence of a residual exotherm in a DSC scan. The films in the present study were also cured for one hour, after which a DSC scan of each film was performed. At this point, some of the films had a residual exotherm above $350^{\circ} \mathrm{C}$, the temperature range in which the phenylethynyl groups react (Figure VIII). These incompletely cured films were discarded, and new films were cast and cured for 90 minutes at $350^{\circ} \mathrm{C}$. At this point, DSC scans showed no exotherms and higher $T_{g} s$, as seen in Figure IX.

\section{Molecular Weight Determination:}

Gel permeation chromatography was performed on the two nonblended oligomers that were soluble in chloroform, which were $90 / 10$ and 100/0. Two runs were performed on each backbone, and the average values are reported in Table I.

The number-average molecular weight, $\mathrm{M}_{n}$, was slightly higher for the $100 / 0$ than for the $90 / 10,5100 \mathrm{vs} .4900 \mathrm{~g} / \mathrm{mol}$. Both values are lower than the $6000 \mathrm{~g} / \mathrm{mol} \mathrm{M}_{\mathrm{n}}$ that was calculated. The cause of this discrepancy is unknown but may be due to small amounts of impurities in the monomers, error in the weighing and transfer of the monomers to the reaction vessel, or error in the GPC/molecular weight analysis. 
The $80 / 20$ oligomer formed a slightly cloudy solution in chloroform with a white ring of opaque, insoluble material that separated and went to the top of the solution. An attempt was made to determine what fraction of the weighed material contributed to the insoluble white ring in the solution. The clear solution was pipetted off leaving the white precipitate which was then washed with chloroform and allowed to settle out again. The process was repeated several times before the mixture was decanted to a dried and tared beaker and dried for several hours. The solubility of the $80 / 20$ was found to be $94.4 \%$. As expected, increasing the biphenol content in the polymer backbone decreases its solubility. This may explain why the $100 / 0$ and $90 / 10$ were soluble and the $80 / 20$ was not.

\section{Characterization:}

Solvent resistance and glass transition temperatures of the cured films were measured, and tensile strength and modulus tests were performed on the films at room temperature and $177^{\circ} \mathrm{C}$. Each of these properties was expected to increase with the addition of the reactive diluents, assuming that a higher concentration of phenylethynyl groups would lead to a higher crosslink density. 


\section{Solvent Resistance}

Resistance to toluene, methylethyl ketone (MEK), jet fuel (JP5), and hydraulic fluid (Chevron HyJet IV) was tested by measuring the relative increase in the linear dimensions as the samples swelled. Results of these tests appear in Tables II to $V$. The overall solvent resistance was best for the films containing $80 / 20$ and worst for the blends containing 100/0. This result is attributed to the increased content of rigid biphenol units.

In all but three isolated cases, the films tested which contained $80 / 20$ or $90 / 10$ showed resistance to jet fuel and hydraulic fluid (less than three percent swelling after 48 hours of exposure). Films containing $100 / 0$ were less resistant to these two solvents, with a maximum of seven percent swelling.

The blends which contained $80 / 20$ showed, in most cases, an improved resistance to both toluene and MEK over the nonblended $80 / 20 \mathrm{film}$. The swelling after exposure to toluene was $18 \%$ in the non-blended $80 / 20 \mathrm{film}$ and was less than one percent with $20 \mathrm{~A}-80 / 20$ and $20 \mathrm{C}-80 / 20$. The non-blended $80 / 20$ film swelled $23 \%$ with exposure to MEK, while the cured film of 10E-80/20 swelled 118. All blends of $A$ and $C$ with $80 / 20$ (10A$80 / 20,20 \mathrm{~A}-80 / 20,10 \mathrm{C}-80 / 20$, and $20 \mathrm{C}-80 / 20$ ) swelled 15 to $16 \%$. This amount of swelling is significant, but it is an 
improvement over the non-blended oligomers.

Four blended $90 / 10$ films (10A-90/10, 20A-90/10, 20B-90/10, and 10E-90/10) were more resistant to toluene than the control, while the others were about the same. The largest improvements were seen in $10 \mathrm{~A}-90 / 10$ and $20 \mathrm{~B}-90 / 10$, with swelling decreasing from $33 \%$ in the control to 6 and $4 \%$, respectively. Some blended 90/10 films (10A-90/10, 20A-90/10, 20B-90/10, and 20C-90/10) showed a slight improvement in resistance to MEK, swelling 15 to $17 \%$ versus $20 \%$ swelling in the control. The resistance of the other blended $90 / 10$ films to MEK did not differ significantly from the control.

In most cases, the resistance of $100 / 0$ to toluene and MEK showed significant improvement with the addition of $20 \%$ of a diluent, but not with the addition of 10\%. The 20B-100/0, for example, swelled only $3 \%$ in toluene, compared to $34 \%$ swelling of the non-blended $100 / 0$ film. The largest improvements to MEK resistance in $100 / 0$ blends were seen in 20B-100/0 and 20E$100 / 0$ films, each of which swelled $18 \%$ while the control swelled $32 \%$.

The blends containing PE-D showed very little resistance to either toluene or MEK, and often there was not enough of the film left to measure after two days of exposure. This result was unexpected, assuming all diluents would increase 
crosslinking. However, due to the size and structure of the molecule, its contribution to an improvement in solvent resistance was not expected to be as great as that of the other diluents. The PE-D molecule is much larger than the other diluents, giving the solvent molecules more space to penetrate the network structure between the phenylethynyl units. Also, the structure of the diluent gave it a high solubility before cure, so the same effect after cure was not surprising .

The best overall solvent resistance was achieved with the blends of $80 / 20$ with diluents $A, B, C$, and E.

\section{Glass Transition Temperatures}

The glass transition temperatures $\left(T_{g} S\right)$ of the films are shown in Table VI, along with the change in $T_{g}$ from the control. The $T_{g} s$ of the non-blended films were expected to decrease with increasing biphenol content, in agreement with previous work. ${ }^{21}$ This trend was seen to some extent, with the $80 / 20$ having the lowest $T_{g}$ of the three non-blended films. The $T_{g} s$ of $90 / 10$ and $100 / 0$, however, were the same.

Due to the expected increase in crosslink density, the $T_{g} s$ of films made from blends were expected to increase over the controls. In most cases, though, the opposite effect was seen. Of the 30 blended films studied, only six displayed an 
increase in $T_{g}$. The most significant increases were seen in the films made from blends of diluents $A$ and $B$ with the $80 / 20$ copolymer. The highest $T_{g} s$ observed were 253 and $254^{\circ} \mathrm{C}$ in $10 \mathrm{~A}-80 / 20$ and $20 \mathrm{~A}-80 / 20$, respectively. These two films also displayed better solvent resistance than most of the other films. Both of these trends, increased $T_{g}$ and increased solvent resistance, indicate an increase in crosslink density. Since PE-A has the lowest molecular weight of any of the diluents, its contribution to final crosslink density is expected to be the highest, and therefore so are the $T_{g}$ and solvent resistance of the corresponding blends.

While the increase in $T_{g}$ of the aforementioned films is easily explained, the lack of increase in the $T_{g} s$ of the other films is difficult to justify. It is interesting to note that while increasing the $\mathrm{BPF} / \mathrm{BP}$ ratio appears to give the non-blended films higher $T_{g} s$, the $T_{g} s$ of the blends containing $P E-D$, which is made from the same BPF used in the oligomer backbones, were very low. They dropped an average of $10^{\circ} \mathrm{C}$ as compared to the corresponding non-blended films, a larger drop than was seen with any other diluent. This can be partially explained by the fact that PE-D has a higher molecular weight than any other diluent, so the crosslink density of a PE-D containing blend would not be as high as that of a blend with the same weight percent of a different diluent. However, it appears from these data that the BPF unit alone is not responsible for 
the increase in $T_{g}$ seen in the $100 / 0$ film. The increase in $T_{g}$ is only seen when the BPF is a part of the oligomer backbone, not when it becomes a part of the network through a BPFcontaining diluent.

\section{Tensile Properties}

The $80 / 20$ and $90 / 10$ films and the films made from $80 / 20$ and $90 / 10$ blends were tested for thin-film tensile modulus, strength, and percent strain at break. Room temperature results are summarized in Tables VII to IX, and results at $177^{\circ} \mathrm{C}$ appear in Tables $\mathrm{X}$ to XII. Due to the poor solvent resistance of the $100 / 0$ polymer and the blends using that polymer, these materials were not included in any further studies.

The modulus values obtained at room temperature did not appear to vary as a direct result of changing the diluent, the polymer backbone, or the percent of diluent in the blend. There was significant scatter in the data, presumably due to film quality. Since several of the diluents were insoluble in all available solvents, many of the films were cast from cloudy mixtures. Although the cured film appeared to be macroscopically homogeneous, modulus values may have been affected by microscopic variations in structure. Casting at lower solids content did not appear to improve solubility enough that a difference in film quality was seen. One goal 
of this work was to develop materials with improved solvent resistance which made solution casting of films difficult. Melt processing of these materials is envisioned as the most practical processing method for the long term.

In most cases, the films made from the blends had modulus values at room temperature that were not significantly different from the moduli of the controls. These values were $360 \pm 40$ and $390 \pm 20 \mathrm{ksi}$ for $80 / 20$ and $90 / 10$ films. The exceptions to this were $10 \mathrm{~A}-80 / 20$ and $10 \mathrm{~A}-90 / 10$ films. A modulus of $470 \pm 80 \mathrm{ksi}$ was achieved from the film of the 10A$90 / 10$ blend. Its resistance to toluene and its $T_{g}$, however, were not as high as that of $10 \mathrm{~A}-80 / 20$, which had a modulus of $423 \pm 2 \mathrm{ksi}$. This falls within the confidence interval of the larger value, and both are definite improvements over the nonblended $80 / 20$ and $90 / 10$ films.

Several improvements in modulus were seen at $177^{\circ} \mathrm{C}$ when compared to the controls, which displayed moduli of $257 \pm 10$ and $258 \pm 1 \mathrm{ksi}$, respectively. The largest average value, $328 \mathrm{ksi}$, was seen in 10A-90/10 film. However, its large confidence interval, $141 \mathrm{ksi}$, encompasses values obtained from all films. Its high average, therefore, may not be as significant as many others with lower averages and smaller confidence intervals. The other blends containing PE-A also had improved averages as compared to the controls, as did the $20 \mathrm{~B}-80 / 20 \mathrm{film}$. The 10A- 
$80 / 20,20 \mathrm{~A}-80 / 20$, and $20 \mathrm{~B}-80 / 20$ films had the highest $\mathrm{T}_{\mathrm{g}} \mathrm{s}, 252$ to $254^{\circ} \mathrm{C}$. A high $\mathrm{T}_{\mathrm{g}}$ often leads to desirable properties at elevated temperatures. This, combined with a high crosslink density in the PE-A blends and the rigid biphenol unit in the $\mathrm{PE}-\mathrm{B}$ blend, led to excellent retention of modulus at $177^{\circ} \mathrm{C}$.

All of the blends made with PE-E also had significantly higher moduli at $177^{\circ} \mathrm{C}$ than the controls. This is a surprising result, because the room temperature modulus values were not higher than the controls and the $\mathrm{T}_{\mathrm{g}} \mathrm{s}$ were lower. Apparently, the high crosslink density achieved with the trifunctional PE$E$ diluent allowed it to retain a large percentage of its modulus at elevated temperature.

The strength of the $90 / 10$ film was higher than that of $80 / 20$. However, while the addition of a diluent caused the strengths of the $80 / 20$ films to remain the same or increase, a decrease in the strengths of the $90 / 10$ films was seen. This effect was seen to such an extent that each film from a blend containing $80 / 20$ had a higher average strength than the comparable film containing 90/10. These trends were consistent at both room temperature and $177^{\circ} \mathrm{C}$.

At room temperature, the most significant increase in strength was seen in the $10 \mathrm{~A}-80 / 20 \mathrm{film}$. Addition of the diluent increased the strength from $10.2 \pm 1.9 \mathrm{ksi}$ to $13.7 \pm 0.1 \mathrm{ksi}$ and 
the percent strain from less than 4 to over 58. This result indicates that the increase in crosslink density that has been observed is not making the film brittle, a problem commonly found in highly crosslinked networks.

At $177^{\circ} \mathrm{C}$, improvements were seen in many films. The highest strengths were observed in the $10 \mathrm{~A}-80 / 20$ and $20 \mathrm{~A}-80 / 20 \mathrm{films}$. Again, these were expected to perform well at high temperatures since the room temperature properties were good and the $\mathrm{T}_{\mathrm{g}} \mathrm{s}$ were high. Additionally, the 20B-80/20, 10E-80/20 and 10E-90/10 films showed improvements.

Improvements in strengths of films containing PE-E were seen only in $10 \%$ blends. $\mathrm{PE}-\mathrm{E}$ is trifunctional, which leads to a high degree of crosslinking. The lack of improved strength in the $20 \%$ blends is possibly a result of too much crosslinking, which makes the films brittle. The changes in strength among the controls and the 10 and $20 \%$ blends of PE-E follow the trend of strengths first increasing then sharply dropping off as the degree of crosslinking is increased. ${ }^{24}$ It is interesting that, like the modulus, an improvement in strength was seen in PE-E films despite the lowering of the $T_{g}$. It is clear from this that a higher $T_{g}$ does not always correspond to a higher retention of properties at elevated temperatures.

At room temperature, there was no difference between the yield 
stress and break stress of the controls, indicating a brittle failure mode. Although the blended films had a higher crosslink density, which would normally lead to decreased toughness, most of the blended films exhibited strain hardening, which is an increase in strength after yielding. Strain hardening was seen in all blends of PE-E and the $20 \%$ blends of $\mathrm{PE}-\mathrm{A}$ and $\mathrm{PE}-\mathrm{B}$. The characteristic stress-strain curves for these two types of failure are illustrated in Figure $X$ (c) and (d) ${ }^{27}$ One measure of toughness is the area under a stress-strain plot. Since strain hardening increases the total area under the curve, it is indicative of an increase in toughness.

At $177^{\circ} \mathrm{C}$, the $80 / 20$ and $90 / 10$ copolymers exhibited a small amount of strain hardening. While the extent of strain hardening increased in the $80 / 20$ blended films as compared to the control, the $90 / 10$ blended films did not strain harden. Although the non-blended $90 / 10$ film had a higher degree of strain hardening than the $80 / 20$, each $80 / 20$ blended film exhibited more strain hardening than the corresponding 90/10 blended film.

\section{Rheology}

A parallel plate rheometer was used to determine the minimum melt viscosity of the blended and non-blended powders. Since the blends containing the $80 / 20$ copolymer backbone 
consistently had better properties that those containing the $90 / 10$ or $100 / 0$ backbones, the latter materials were excluded from this study.

Since $P E-B$ has such a high melting point $\left(344^{\circ} \mathrm{C}\right)$ and low solubility, its contribution to lowering melt viscosity was expected to be minimal. A lower melt viscosity is only achieved when the diluent becomes incorporated into the oligomer system by dissolving in the liquid oligomers or by melting. The solubility of $\mathrm{PE}-\mathrm{B}$ in organic solvents was low enough that a recrystallization solvent could not be found, so it was not expected to dissolve in the oligomers. This is supported by the existence of an endotherm (PE-B melt) above the $\mathrm{T}_{\mathrm{g}}$ of the uncured blended powder in a DSC run of 10B$80 / 20$, Figure XI, which illustrates that the diluent has not dissolved in the melted oligomer.

PE-B could plasticize the oligomers above the melting point of the diluent, but cure of the phenylethynyl groups begins at or below the melting point of $\mathrm{PE}-\mathrm{B}$. This would give a material with a very small processing window, making processing very difficult. This can also be seen in the DSC scan of 10B$80 / 20$, Figure XI, where the endotherm (melting point of PE-B) is directly before the exotherm (curing reaction of the phenylethynyl groups). By comparison, the DSC scan of 10A- 
$80 / 20$, Figure XII, illustrates the wide processing window available with a lower melting diluent. Therefore, PE-B containing diluents were eliminated from this study.

Although PE-D has the lowest melting point and highest solubility of the five diluents studied, it was eliminated from this stage of the study due to its lack of contribution to solvent resistance, one of the primary goals of the study.

For the first step of the rheology study, only $10 \mathrm{~A}-80 / 20,10 \mathrm{C}-$ $80 / 20$, and $10 \mathrm{E}-80 / 20$ were tested, along with the $80 / 20$ control. With an initial scan from room temperature to $400^{\circ} \mathrm{C}$, $10 \mathrm{~A}-80 / 20$ was found to have the lowest minimum melt viscosity of the four systems tested. Since the viscosity was not as low as current technology requires for resin transfer molding (RTM), the $20 \mathrm{~A}-80 / 20$ was added to the second step of the rheology study. This study simulated actual processing temperatures, with a ramp from room temperature to $371^{\circ} \mathrm{C}$ and a hold at that temperature until after the gel point. Results of this study are shown in Table XIII. As expected, the melt viscosity for $20 \mathrm{~A}-80 / 20$ was even lower than that of $10 \mathrm{~A}-80 / 20$. The minimum melt viscosity of the non-blended $80 / 20$ was 700 poise, while that of $10 \mathrm{~A}-80 / 20$ was 200 poise and $20 \mathrm{~A}-80 / 20$ was 70 poise. The plots of viscosity vs. time for these three systems can be seen in Figures XIII, XIV, and XV where the 
storage and loss moduli, G' and G", have both been plotted as a function of time.

The minimum melt viscosity of $10 \mathrm{C}-80 / 20$ was also lower than that of the control, about 280 poise, but not as low as that of the 10A-80/20. Therefore, the $20 \mathrm{C}-80 / 20$ was not added to the second step of the rheology study.

The 10E-80/20 had a minimum viscosity of 12,000 poise, much higher than that of the control. The diluent used in this blend, PE-E, is trifunctional. The other four diluents are difunctional. The PE-E containing blend, therefore, reached the gel point much more quickly than the other blends. In these rheological studies, the gel point of $10 \mathrm{E}-80 / 20$ was reached after 45 minutes, while the other four systems that were studied gelled after 78 to 88 minutes. This result can be seen in the 10E-80/20 viscosity vs. time plot, Figure XVI.

\section{Adhesive Specimens}

The Ti/Ti tensile shear strengths were determined for 20A$80 / 20,10 \mathrm{~A}-80 / 20$, and the non-blended $80 / 20$ materials. Each was processed at 15,25 , and 50 psi to determine the best processing conditions. The adhesive strengths obtained, which ranged from 780 to 1610 psi, were disappointing because a previous study ${ }^{21}$ reported strengths of up to 2385 psi for the 
same $80 / 20$ copolymer under the same conditions. A poor quality scrim cloth is the most likely reason for the discrepancy in adhesive values. Also, the very thin bondlines, 2.6 to $4.4 \mathrm{mils}$, indicate that the adhesive was flowing out of the sides of the specimens during processing. The bondline thickness of $80 / 20$ and $10 \mathrm{~A}-80 / 20$ decreased as bonding pressure increased, as expected. In the case of 20A$80 / 20$, however, the bondline remained about the same, $2.7 \pm$ 0.3 to $3.2 \pm 0.4$, for all pressures. This indicates that too much flow was occurring, even at 15 psi:

In order to decrease the amount of flow, a set of specimens was held at $371^{\circ} \mathrm{C}$ to allow some reaction to take place so that the viscosity could increase before applying the 15 psi pressure. Since the initial viscosities of the systems were different, the hold times were customized for each system. From the rheology data (Figures XIII to XV), the viscosity of the curing system can be determined at any point along the hold at $371^{\circ} \mathrm{C}$. A constant viscosity of 1000 poise was chosen as the point at which pressure would be applied to all three systems. This meant that the $20 \mathrm{~A}-80 / 20$ would be held at $371^{\circ}$ for $15 \mathrm{~min}$, the $10 \mathrm{~A}-80 / 20$ for $12 \mathrm{~min}$, and the $80 / 20$ for $5 \mathrm{~min}$. After the hold, 15 psi was applied and held for 45, 48, and 55 min, respectively, to give a total of $1 \mathrm{~h}$ at $371^{\circ} \mathrm{C}$. 
Although the bondline thickness only increased for the $20 \mathrm{~A}-$ $80 / 20$ as compared to the specimens bonded with 15 psi and no initial hold, the strengths of all three materials increased when the hold was added. The same processing conditions were used for the rest of the adhesive specimens, which were tested at room temperature after 48 hours of exposure to toluene, MEK, jet fuel, or hydraulic fluid and at $177^{\circ} \mathrm{C}$.

The adhesive strengths at room temperature were highest for 20A-80/20 (1530 psi) and lowest for 80/20 (1090 psi). This is the expected outcome and is assumed to be a result of the reaction of the phenylethynyl groups. In five of the six test conditions, the average value of $20 \mathrm{~A}-80 / 20$ exceeded the average value of $10 \mathrm{~A}-80 / 20$. In most cases, though, the strengths of $20 \mathrm{~A}-80 / 20$ and $10 \mathrm{~A}-80 / 20$ fell within the $90 \%$ confidence limits of one another, so the differences in strength may not be significant. The improvements in 10A$80 / 20$ and $20 \mathrm{~A}-80 / 20$ blends over the non-blended $80 / 20$, however, are significant in at least four of the six test conditions. The two conditions which are questionable, the MEK soak and the jet fuel soak, have $80 / 20$ shear strength values with a high degree of scatter as shown in the exceptionally large confidence intervals $1920 \pm 430 \mathrm{psi}$ and $690 \pm 430 \mathrm{psil}$. Although these average values are less than the strengths of the blended adhesive specimens, it is difficult 
to state conclusively that the differences are statistically significant.

The adhesive strengths of the samples tested at $177^{\circ} \mathrm{C}$ were surprisingly high, displaying an increase of between 25 and $50 \%$ as compared to the corresponding room temperature values. This effect has been observed in a previous study of the nonblended $80 / 20$ polymer ${ }^{21}$ where increases were $33 \%$ at $150^{\circ} \mathrm{C}$ and $17 \%$ at $177^{\circ} \mathrm{C}$, comparable to the increases observed here. A possible explanation of this effect is that the adhesive becomes tougher with increasing temperature. As the $T_{g}$ is approached, molecular motion increases. This allows the polymer chains to absorb more energy, thus increasing toughness and reducing the probability of a brittle fracture in the adhesive. The decrease in room temperature adhesive strengths as compared to those in the previous study also indicates that the adhesive may be brittle.

As with the adhesive strengths, the percent retention of strength (calculated using the strength of the adhesive after soaking and the strength of the corresponding adhesive at room temperature) was, in general, highest for $20 \mathrm{~A}-80 / 20$ and lowest for the non-blended $80 / 20$. This trend existed with all solvents except MEK. Although the average strengths of the MEK-soaked specimens followed the same trend as the others, 
the percent retention was the reverse of what was expected, with retentions of 73,76 and $85 \%$ for $20 \mathrm{~A}-80 / 20,10 \mathrm{~A}-80 / 20$, and non-blended $80 / 20$ materials. This result is not well understood, but there was a lot of scatter in the MEK data, and the numbers may not be significantly different from one another.

of the three materials and four solvents used, the only cases where swelling was observed in the previously discussed solvent resistance study were $20 \mathrm{~A}-80 / 20$ and $10 \mathrm{~A}-80 / 20$ films in MEK with $16 \%$ swelling, $80 / 20$ copolymer in MEK with $23 \%$ swelling, and $80 / 20$ copolymer in toluene with $18 \%$ swelling. The retention of strength, therefore, was expected to be the lowest for MEK, then toluene, and about the same for jet fuel and hydraulic fluid.

Although the percent retention of strengths of the $20 \mathrm{~A}-80 / 20$ blend may be slightly higher for toluene (79\%) than for MEK (73\%), the differences may be within experimental error. The retention of strength of the $10 \mathrm{~A}-80 / 20$ blend in toluene (75\%) was about the same as that for MEK (76\%). The strength retention of the MEK-soaked samples was expected to be much lower than that of toluene because the films of $20 \mathrm{~A}-80 / 20$ and 10A-80/20 did not swell in toluene at all, but swelled significantly in MEK. Although there are a number of things 
that can affect bond strength, this is difficult to explain. While swelling appears to be deteriorating the adhesive strengths of the MEK-soaked samples, toluene could be affecting the bond in another way, such as at the Ti-adhesive interface, which would not necessarily cause the films to swell.

The $20 \mathrm{~A}-80 / 20$ and $10 \mathrm{~A}-80 / 20$ adhesive samples exposed to jet fuel had a slightly higher retention of strengths (83 and $81 \%$, respectively) than those exposed to toluene. The highest retention after a solvent soak was attained with hydraulic fluid, giving strength retentions of 94 and $93 \%$ for $20 \mathrm{~A}-80 / 20$ and $10 \mathrm{~A}-80 / 20$ blends. It is interesting that there was this much difference in the effects of toluene, jet fuel, and hydraulic fluid since neither the $20 \mathrm{~A}-80 / 20$ nor the $10 \mathrm{~A}-80 / 20$ blends displayed swelling in any of the three solvents. Additionally, the non-blended $80 / 20$ copolymer, which did not swell in jet fuel or hydraulic fluid, lost much more strength in these two solvents than the corresponding blended specimens, showing a strength retention of 64 and $78 \%$ after exposure to jet fuel and hydraulic fluid, respectively. This finding appears to demonstrate that although swelling tests can be used as a guideline to determine what materials are resistant to solvents, a test such as the present one is more sensitive to the effects of solvent exposure. 


\section{Conclusions}

The purpose of this study was to improve properties of phenylethynyl-terminated arylene ether (PETAE) oligomers by blending with reactive diluents. The goal was to increase solvent resistance, glass transition temperature, strength and modulus while lowering the melt viscosity to provide easier processing.

The study began with five diluents and three oligomer backbones. Each was blended at 10 and 20 weight percent of diluent to oligomer. Various studies allowed for the subsequent elimination of oligomer backbones and diluents, leaving two blends at the end of the study which best met the goals of the research.

The degree to which cured films of the blends swelled with exposure to each of four solvents was studied. The $80 / 20$ and 90/10 backbones blended with diluents $A, B, C$, and $E$ showed the best solvent resistance. Several films were resistant to jet fuel and hydraulic fluid. Some showed resistance to toluene. Although all films swelled with exposure to MEK, the 
degree of swelling decreased with addition of diluents.

Glass transition temperatures of cured films appeared to vary with the polymer backbone and diluent used. While the $\mathrm{T}_{g}$ decreased in 24 of the 30 blends as compared to the controls, the $80 / 20$ backbone and diluents $A$ and $B$ gave significant improvements in $\mathrm{T}_{g}$. A glass transition temperature of $254^{\circ} \mathrm{C}$ was observed from $20 \mathrm{~A}-80 / 20$, a $16^{\circ} \mathrm{C}$ increase over the nonblended $80 / 20$ copolymer.

Tensile modulus values at room temperature were about the same as those of non-blended films. At $177^{\circ} \mathrm{C}$, many blends displayed improvements in modulus as compared to the controls. Improvements in strengths were seen at both room temperature and $177^{\circ}$. Several blends also displayed strain hardening in film testing.

From rheology data, it was determined that the minimum melt viscosity of the $80 / 20$ oligomer backbone decreased by an order of magnitude with the addition of 20 wt $\%$ of diluent $A$, from 700 to 70 poise, which is within an order of magnitude of the viscosity needed for RTM processing.

$\mathrm{Ti} / \mathrm{Ti}$ tensile shear strengths were higher for the adhesives containing 10 or 20 wt $\%$ of diluent $A$ compared to the nonblended $80 / 20$ copolymer. The blended adhesives also retained 
more of their original strength after exposure to solvents. Al1 adhesive strengths increased when tested at $177^{\circ} \mathrm{C}$ as compared to the strengths at room temperature.

The blends of 10 and 20 wt 8 of diluent $A$ with the $80 / 20$ PETAE oligomer backbone (20A-80/20 and 10A-80/20) had the best overall properties. A summary of the properties of the 10A$80 / 20,20 \mathrm{~A}-80 / 20$, and non-blended $80 / 20$ materials appear in the following table.

\begin{tabular}{|c|c|c|c|}
\hline & $20 A-80 / 20$ & $10 A-80 / 20$ & $80 / 20$ \\
\hline \begin{tabular}{|r} 
Swelling \\
Toluene \\
MEK \\
Jet fuel \\
Hydraulic fluid
\end{tabular} & $\begin{array}{c}\text { none } \\
16 \% \\
\text { none } \\
\text { none }\end{array}$ & $\begin{array}{c}\text { none } \\
16 \% \\
\text { none } \\
\text { none }\end{array}$ & $\begin{array}{l}18 \% \\
23 \% \\
\text { none } \\
\text { none }\end{array}$ \\
\hline $\mathrm{T}_{\mathrm{g}},{ }^{\circ} \mathrm{C}$ & 253 & 254 & 238 \\
\hline $\begin{array}{l}\text { Tensile modulus, } \mathrm{RT} \\
\left(177^{\circ} \mathrm{C}\right), \mathrm{ksi}\end{array}$ & $\begin{array}{l}338 \\
(298)\end{array}$ & $\begin{array}{c}423 \\
(278)\end{array}$ & $\begin{array}{c}365 \\
(257)\end{array}$ \\
\hline $\begin{array}{l}\text { Tensile strength, RT } \\
\left(177^{\circ} \mathrm{C}\right), \mathrm{ksi}\end{array}$ & $\begin{array}{l}10.6 \\
(7.1)\end{array}$ & $\begin{array}{l}13.7 \\
(7.8)\end{array}$ & $\begin{array}{l}10.2 \\
(5.3)\end{array}$ \\
\hline $\begin{array}{l}\text { Minimum melt viscosity, } \\
\text { poise }\end{array}$ & 70 & 200 & 700 \\
\hline $\begin{array}{r}\text { Adhesive strengths, psi } \\
\mathrm{RT} \\
177^{\circ} \mathrm{C} \\
\text { Toluene } \\
\text { MEK } \\
\text { Jet fuel } \\
\text { Hydraulic fluid }\end{array}$ & $\begin{array}{l}1530 \\
1920 \\
1210 \\
1120 \\
1270 \\
1450 \\
\end{array}$ & $\begin{array}{l}1400 \\
2080 \\
1040 \\
1070 \\
1140 \\
1300 \\
\end{array}$ & $\begin{array}{l}1090 \\
1470 \\
730 \\
920 \\
690 \\
850 \\
\end{array}$ \\
\hline
\end{tabular}


Table I

Summary of Molecular Weight Results

\begin{tabular}{|c|c|c|c|c|}
\hline Sample & $\begin{array}{c}\mathrm{M}_{\mathrm{n}} \\
(\mathrm{g} / \mathrm{mol})\end{array}$ & $\begin{array}{c}\mathrm{M}_{\mathrm{w}} \\
(\mathrm{g} / \mathrm{mol})\end{array}$ & Polydispersity & $\begin{array}{c}\text { Intrinsic } \\
\text { Viscosity } \\
(\mathrm{dL} / \mathrm{g})\end{array}$ \\
\hline $100 / 0$ & 5100 & 11400 & 2.2 & 0.218 \\
\hline $90 / 10$ & 4900 & 12000 & 2.5 & 0.226 \\
\hline
\end{tabular}


Table II

Resistance of Cured Films to Jet Fuel

\begin{tabular}{|c|c|c|c|}
\hline Material & $\begin{array}{c}\text { Percent } \\
\text { swelling }\end{array}$ & Material & $\begin{array}{c}\text { Percent } \\
\text { swelling }\end{array}$ \\
\hline & & $10 c-80 / 20$ & no swelling \\
\hline $80 / 20$ & no swelling & $20 c-80 / 20$ & no swelling \\
\hline $90 / 10$ & 5 & $10 c-90 / 10$ & no swelling \\
\hline \multirow[t]{2}{*}{$100 / 0$} & 4 & $20 \mathrm{C}-90 / 10$ & no swelling \\
\hline & & $10 \mathrm{C}-100 / 0$ & 7 \\
\hline & \multirow{2}{*}{ no swelling } & $20 \mathrm{C}-100 / 0$ & 6 \\
\hline $10 A-80 / 20$ & & \multirow[b]{2}{*}{$10 D-80 / 20$} & \\
\hline $20 \mathrm{~A}-80 / 20$ & \multirow{2}{*}{$\begin{array}{c}\text { no swelling } \\
5\end{array}$} & & 4 \\
\hline $10 A-90 / 10$ & & $20 \mathrm{D}-80 / 20$ & no swelling \\
\hline $20 A-90 / 10$ & no swelling & $10 D-90 / 10$ & \multirow{3}{*}{$\begin{array}{c}3 \\
\text { no swelling } \\
3\end{array}$} \\
\hline $10 A-100 / 0$ & 3 & $20 D-90 / 10$ & \\
\hline \multirow[t]{2}{*}{$20 A-100 / 0$} & 5 & $10 D-100 / 0$ & \\
\hline & \multirow{2}{*}{ no swelling } & $20 D-100 / 0$ & no swelling \\
\hline $10 \mathrm{~B}-80 / 20$ & & & \\
\hline $20 \mathrm{~B}-80 / 20$ & \multirow{2}{*}{$\begin{array}{l}\text { no swelling } \\
\text { no swelling }\end{array}$} & $10 E-80 / 20$ & no swelling \\
\hline $10 B-90 / 10$ & & $20 E-80 / 20$ & no swelling \\
\hline $20 B-90 / 10$ & no swelling & $10 E-90 / 10$ & no swelling \\
\hline $10 \mathrm{~B}-100 / 0$ & \multirow{2}{*}{$\begin{array}{l}\text { no swelling } \\
\text { no swelling }\end{array}$} & $20 \mathrm{E}-90 / 10$ & 3 \\
\hline \multirow[t]{2}{*}{$20 B-100 / 0$} & & $10 E-100 / 0$ & 3 \\
\hline & & $20 \mathrm{E}-100 / 0$ & no swelling \\
\hline
\end{tabular}




\section{Table III}

Resistance of Cured Films to Hydraulic Fluid

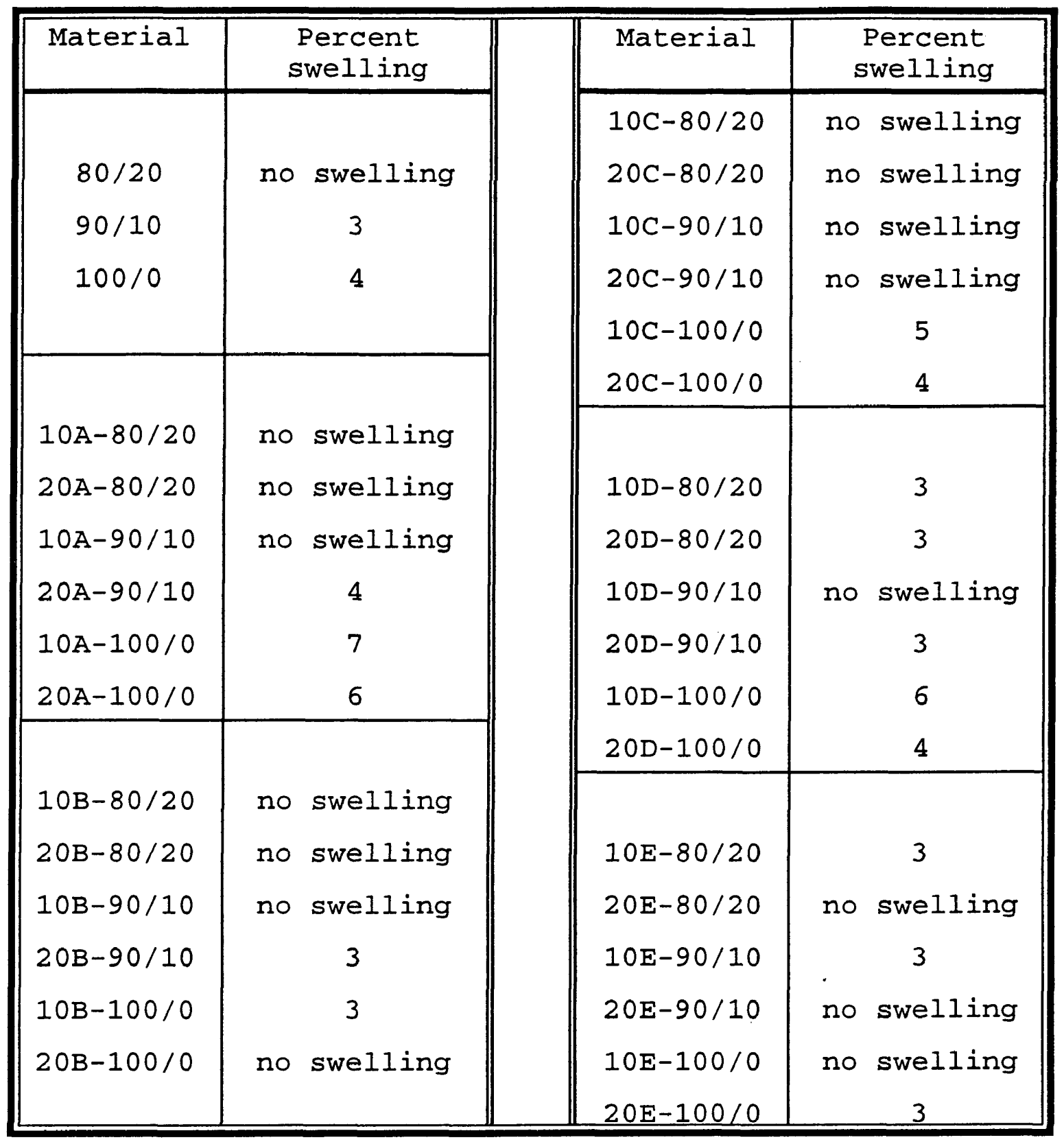


Table IV

Resistance of Cured Films to Toluene

\begin{tabular}{|c|c|c|c|}
\hline Material & $\begin{array}{l}\text { Percent } \\
\text { swelling }\end{array}$ & Material & $\begin{array}{l}\text { Percent } \\
\text { swelling }\end{array}$ \\
\hline & & $10 C-80 / 20$ & no swelling \\
\hline $80 / 20$ & 18 & $20 \mathrm{C}-80 / 20$ & no swelling \\
\hline $90 / 10$ & 33 & $10 C-90 / 10$ & 32 \\
\hline \multirow[t]{2}{*}{$100 / 0$} & 34 & $20 c-90 / 10$ & 37 \\
\hline & & $10 C-100 / 0$ & $\star \star$ \\
\hline & & $20 \mathrm{C}-100 / 0$ & 16 \\
\hline $10 \mathrm{~A}-80 / 20$ & no swelling & & \\
\hline $20 \mathrm{~A}-80 / 20$ & no swelling & $10 D-80 / 20$ & $\star \star \star$ \\
\hline $10 \mathrm{~A}-90 / 10$ & 6 & $20 D-80 / 20$ & 34 \\
\hline $20 \mathrm{~A}-90 / 10$ & 20 & $10 D-90 / 10$ & 37 \\
\hline $10 \mathrm{~A}-100 / 0$ & ** & $20 \mathrm{D}-90 / 10$ & 36 \\
\hline \multirow[t]{2}{*}{$20 \mathrm{~A}-100 / 0$} & 23 & $10 D-100 / 0$ & $\star \star$ \\
\hline & & $20 D-100 / 0$ & 27 \\
\hline $10 B-80 / 20$ & no swelling & & \\
\hline $20 \mathrm{~B}-80 / 20$ & 3 & $10 E-80 / 20$ & 3 \\
\hline $10 B-90 / 10$ & ** & $20 E-80 / 20$ & no swelling \\
\hline $20 B-90 / 10$ & 4 & $10 E-90 / 10$ & 16 \\
\hline $10 B-100 / 0$ & 23 & $20 E-90 / 10$ & 36 \\
\hline \multirow[t]{2}{*}{$20 \mathrm{~B}-100 / 0$} & 3 & $10 E-100 / 0$ & $\star \star$ \\
\hline & & $20 E-100 / 0$ & 40 \\
\hline
\end{tabular}

$\star \star$ Polymer degraded during testing and could not be measured. 


\section{Table V}

Resistance of Cured Films to Methyl Ethyl Ketone

\begin{tabular}{|c|c|c|c|}
\hline Material & $\begin{array}{l}\text { Percent } \\
\text { swelling }\end{array}$ & Material & $\begin{array}{l}\text { Percent } \\
\text { swelling }\end{array}$ \\
\hline & & $10 \mathrm{C}-80 / 20$ & 15 \\
\hline $80 / 20$ & 23 & $20 \mathrm{C}-80 / 20$ & 16 \\
\hline $90 / 10$ & 20 & $10 \mathrm{C}-90 / 10$ & 20 \\
\hline \multirow[t]{2}{*}{$100 / 0$} & 32 & $20 c-90 / 10$ & 16 \\
\hline & & $10 \mathrm{C}-100 / 0$ & 36 \\
\hline & & $20 \mathrm{C}-100 / 0$ & $\star \star$ \\
\hline $10 \mathrm{~A}-80 / 20$ & 16 & & \\
\hline $20 A-80 / 20$ & 16 & $10 D-80 / 20$ & $\star \star$ \\
\hline $10 A-90 / 10$ & 17 & $20 D-80 / 20$ & $\star \star$ \\
\hline $20 A-90 / 10$ & 16 & $10 D-90 / 10$ & 22 \\
\hline $10 A-100 / 0$ & 36 & $20 D-90 / 10$ & $\star \star$ \\
\hline $20 A-100 / 0$ & 22 & $10 D-100 / 0$ & $\star \star$ \\
\hline \multirow{2}{*}{$10 B-80 / 20$} & \multirow[b]{2}{*}{20} & $20 D-100 / 0$ & 24 \\
\hline & & \multirow[b]{2}{*}{$10 E-80 / 20$} & \multirow[b]{2}{*}{11} \\
\hline $20 \mathrm{~B}-80 / 20$ & 17 & & \\
\hline $10 B-90 / 10$ & 25 & $20 E-80 / 20$ & 17 \\
\hline $20 B-90 / 10$ & 15 & $10 E-90 / 10$ & 18 \\
\hline $10 B-100 / 0$ & 19 & $20 E-90 / 10$ & 18 \\
\hline \multirow[t]{2}{*}{$20 B-100 / 0$} & 18 & $10 \mathrm{E}-100 / 0$ & 32 \\
\hline & & $20 E-100 / 0$ & 18 \\
\hline
\end{tabular}

* Polymer degraded during testing and could not be measured. 
Table VI

Glass Transition Temperatures of Cured Films

\begin{tabular}{|c|c|c|c|c|c|}
\hline Material & $\mathrm{T}_{g}\left({ }^{\circ} \mathrm{C}\right)$ & $\begin{array}{l}\text { Change } \\
\text { in } \mathrm{T}_{g}\end{array}$ & Material & $\mathrm{T}_{\mathrm{g}}\left({ }^{\circ} \mathrm{C}\right)$ & $\begin{array}{l}\text { Change } \\
\text { in } T_{g}\end{array}$ \\
\hline & & & $10 \mathrm{C}-80 / 20$ & 239 & +1 \\
\hline $80 / 20$ & 238 & -- & $20 \mathrm{C}-80 / 20$ & 233 & -5 \\
\hline $90 / 10$ & 243 & -- & $10 \mathrm{C}-90 / 10$ & 233 & -10 \\
\hline \multirow[t]{2}{*}{$100 / 0$} & 243 & -- & $20 \mathrm{C}-90 / 10$ & 219 & -24 \\
\hline & & & $10 \mathrm{C}-100 / 0$ & 237 & -6 \\
\hline & & & $20 C-100 / 0$ & 235 & -8 \\
\hline $10 \mathrm{~A}-80 / 20$ & 253 & +15 & & & \\
\hline $20 A-80 / 20$ & 254 & +16 & $10 D-80 / 20$ & 223 & -15 \\
\hline $10 A-90 / 10$ & 241 & -2 & $20 D-80 / 20$ & 222 & -16 \\
\hline $20 A-90 / 10$ & 236 & -7 & $10 D-90 / 10$ & 231 & -12 \\
\hline $10 \mathrm{~A}-100 / 0$ & 237 & -6 & $20 D-90 / 10$ & 231 & -12 \\
\hline \multirow[t]{2}{*}{$20 A-100 / 0$} & 237 & -6 & $10 D-100 / 0$ & 238 & -5 \\
\hline & & & $20 D-100 / 0$ & 241 & -2 \\
\hline $10 B-80 / 20$ & 242 & +4 & & & \\
\hline $20 B-80 / 20$ & 252 & +14 & $10 E-80 / 20$ & 235 & -3 \\
\hline $10 \mathrm{~B}-90 / 10$ & 229 & -14 & $20 E-80 / 20$ & 235 & -3 \\
\hline $20 B-90 / 10$ & 235 & -8 & $10 E-90 / 10$ & 238 & -5 \\
\hline $10 B-100 / 0$ & 237 & -6 & $20 E-90 / 10$ & 231 & -12 \\
\hline \multirow[t]{2}{*}{$20 B-100 / 0$} & 247 & +4 & $10 E-100 / 0$ & 236 & -7 \\
\hline & & & $20 E-100 / 0$ & 237 & -6 \\
\hline
\end{tabular}


Table VII

Tensile Modulus at Room Temperature

\begin{tabular}{|c|c|c|c|}
\hline Material & $\begin{array}{l}\text { Modulus } \\
\text { (ksi) }\end{array}$ & Material & $\begin{array}{l}\text { Modulus } \\
\text { (ksi) }\end{array}$ \\
\hline & & $10 C-80 / 20$ & $380 \pm 17$ \\
\hline $80 / 20$ & $365 \pm 40$ & $20 \mathrm{C}-80 / 20$ & $372 \pm 3$ \\
\hline \multirow[t]{2}{*}{$90 / 10$} & $387 \pm 22$ & $10 C-90 / 10$ & $393 \pm 18$ \\
\hline & \multirow{3}{*}{$\begin{array}{c}423 \pm 2 \\
338 \pm 18\end{array}$} & $20 \mathrm{C}-90 / 10$ & $\star \star$ \\
\hline $10 A-80 / 20$ & & \multirow[b]{2}{*}{$10 D-80 / 20$} & \multirow[b]{2}{*}{$\star \star$} \\
\hline $20 A-80 / 20$ & & & \\
\hline $10 A-90 / 10$ & $474 \pm 83$ & $20 D-80 / 20$ & \multirow{3}{*}{$\begin{array}{c}\star \star \\
376 \pm 29 \\
\star \star\end{array}$} \\
\hline $20 A-90 / 10$ & $358 \pm 15$ & $10 D-90 / 10$ & \\
\hline \multirow[b]{2}{*}{$10 B-80 / 20$} & \multirow[b]{2}{*}{$348 \pm 13$} & $20 D-90 / 10$ & \\
\hline & & & \multirow[b]{2}{*}{$361 \pm 4$} \\
\hline $20 B-80 / 20$ & $339 \pm 20$ & $10 E-80 / 20$ & \\
\hline $10 B-90 / 10$ & $399 \pm 11$ & $20 E-80 / 20$ & $373 \pm 28$ \\
\hline \multirow[t]{2}{*}{$20 B-90 / 10$} & $396 \pm 4$ & $10 E-90 / 10$ & $385 \pm 31$ \\
\hline & & $20 \mathrm{E}-90 / 10$ & $356 \pm 29$ \\
\hline
\end{tabular}

$\star \star$ Acceptable film for measuring tensile properties could not be made. 


\section{Table VIII}

Tensile Strength at Room Temperature

\begin{tabular}{|c|c|c|c|}
\hline Material & $\begin{array}{l}\text { Strength } \\
\text { (ksi) }\end{array}$ & Material & $\begin{array}{l}\text { Strength } \\
\text { (ksi) }\end{array}$ \\
\hline & & $10 C-80 / 20$ & $11.9 \pm 0.6$ \\
\hline $80 / 20$ & $10.2 \pm 1.9$ & $20 C-80 / 20$ & $10.7 \pm 2.2$ \\
\hline \multirow[t]{2}{*}{$90 / 10$} & $12.5 \pm 0.5$ & $10 \mathrm{C}-90 / 10$ & $8.2 \pm 1.9$ \\
\hline & \multirow{5}{*}{$\begin{array}{l}13.7 \pm 0.1 \\
10.6 \pm 2.0 \\
9.6 \pm 3.7 \\
7.4 \pm 2.3\end{array}$} & $20 \mathrm{C}-90 / 10$ & $\star \star$ \\
\hline $10 A-80 / 20$ & & & \\
\hline $20 A-80 / 20$ & & $10 D-80 / 20$ & $\star \star$ \\
\hline $10 A-90 / 10$ & & $20 D-80 / 20$ & ** \\
\hline \multirow[t]{2}{*}{$20 A-90 / 10$} & & $10 D-90 / 10$ & $10.9 \pm 0.9$ \\
\hline & \multirow[b]{2}{*}{$10.9 \pm 1.1$} & $20 D-90 / 10$ & ** \\
\hline $10 \mathrm{~B}-80 / 20$ & & & \\
\hline $20 B-80 / 20$ & $6.9 \pm 2.6$ & $10 E-80 / 20$ & $12.4 \pm 0.9$ \\
\hline $10 \mathrm{~B}-90 / 10$ & $7.6 \pm 0.9$ & $20 E-80 / 20$ & $12.0 \pm 1.0$ \\
\hline \multirow[t]{2}{*}{$20 B-90 / 10$} & $4.5 \pm 0.8$ & $10 E-90 / 10$ & $10.6 \pm 1.0$ \\
\hline & & $20 \mathrm{E}-90 / 10$ & $8.2 \pm 2.3$ \\
\hline
\end{tabular}

** Acceptable film for measuring tensile properties could not be made. 
Table IX

Percent Strain at Room Temperature

\begin{tabular}{|c|c|c|c|}
\hline Material & $\begin{array}{l}\text { Percent } \\
\text { strain at } \\
\text { break }\end{array}$ & Material & $\begin{array}{l}\text { Percent } \\
\text { strain at } \\
\text { break }\end{array}$ \\
\hline & & $10 \mathrm{C}-80 / 20$ & $4.6 \pm 0.5$ \\
\hline $80 / 20$ & $3.8 \pm 0.6$ & $20 C-80 / 20$ & $4.0 \pm 1.0$ \\
\hline \multirow[t]{2}{*}{$90 / 10$} & $4.8 \pm 0.8$ & $10 C-90 / 10$ & $2.4 \pm 0.6$ \\
\hline & \multirow[b]{2}{*}{$5.3 \pm 0.4$} & $20 C-90 / 10$ & $\star *$ \\
\hline $10 \mathrm{~A}-80 / 20$ & & \multirow[b]{2}{*}{$10 \mathrm{D}-80 / 20$} & \multirow[b]{2}{*}{ ** } \\
\hline $20 A-80 / 20$ & $4.2 \pm 1.0$ & & \\
\hline $10 A-90 / 10$ & \multirow{2}{*}{$\begin{array}{l}2.5 \pm 1.4 \\
2.3 \pm 0.8 \\
\end{array}$} & \multirow{2}{*}{$\begin{array}{l}20 D-80 / 20 \\
10 D-90 / 10\end{array}$} & \multirow{3}{*}{$\begin{array}{c}\star \star \\
3.6 \pm 0.6 \\
\star \star\end{array}$} \\
\hline $20 A-90 / 10$ & & & \\
\hline \multirow[b]{2}{*}{$10 B-80 / 20$} & \multirow[b]{2}{*}{$4.4 \pm 0.8$} & $20 D-90 / 10$ & \\
\hline & & \multirow[b]{2}{*}{$10 E-80 / 20$} & \multirow[b]{2}{*}{$5.0 \pm 0.4$} \\
\hline $20 B-80 / 20$ & $2.4 \pm 1.1$ & & \\
\hline $10 B-90 / 10$ & $2.4 \pm 0.4$ & $20 E-80 / 20$ & $4.4 \pm 0.7$ \\
\hline \multirow[t]{2}{*}{$20 B-90 / 10$} & \multirow[t]{2}{*}{$1.4 \pm 0.2$} & $10 E-90 / 10$ & \multirow{2}{*}{$\begin{array}{l}3.3 \pm 0.6 \\
2.7 \pm 1.0 \\
\end{array}$} \\
\hline & & $20 E-90 / 10$ & \\
\hline
\end{tabular}

** Acceptable film for measuring tensile properties could not be made. 


\section{Table $x$}

Tensile Modulus at $177^{\circ} \mathrm{C}$

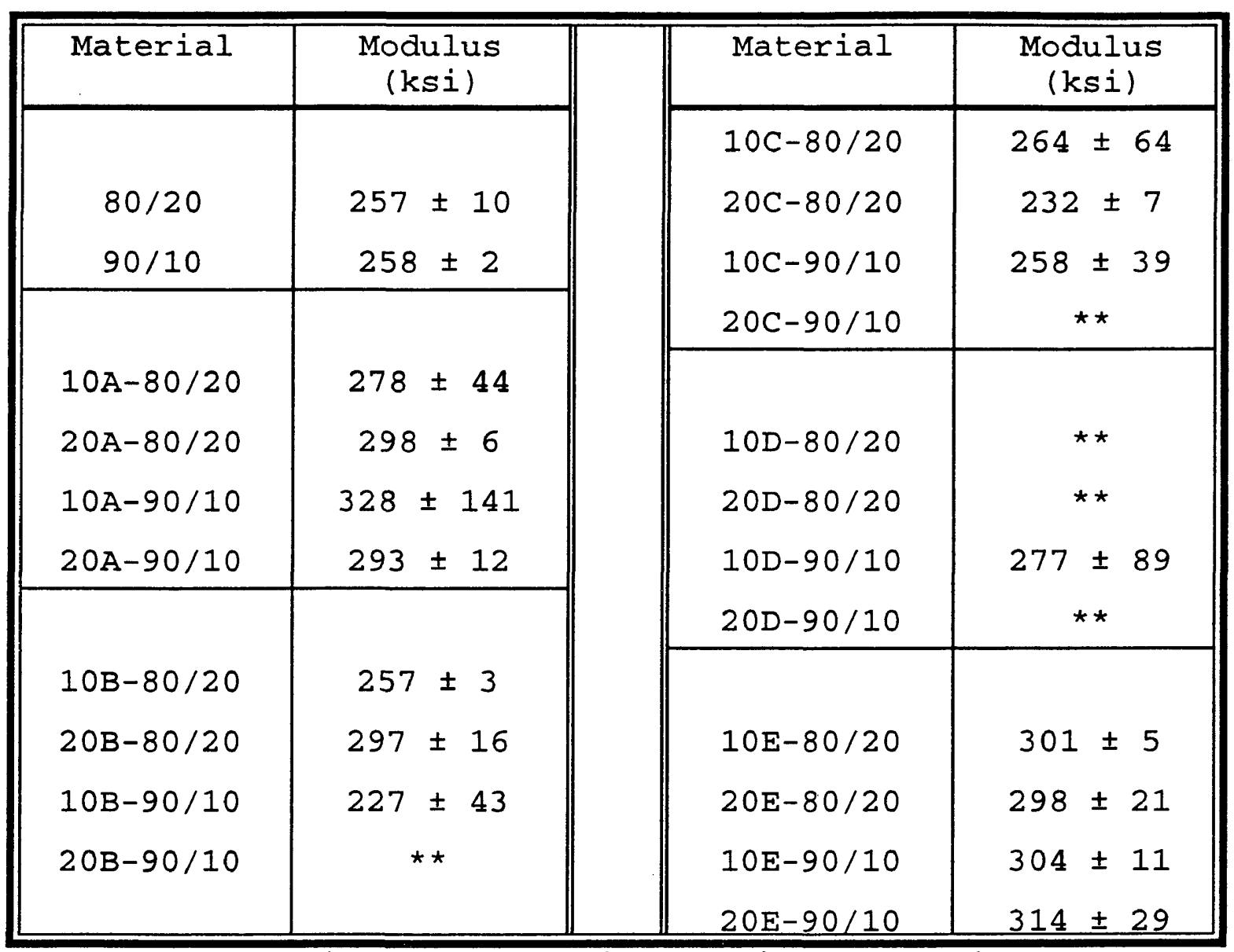

$\star \star$ Acceptable film for measuring tensile properties could not be made. 


\section{Table XI}

Tensile Strength at $177^{\circ} \mathrm{C}$

\begin{tabular}{|c|c|c|c|}
\hline Material & $\begin{array}{l}\text { Strength } \\
\text { (ksi) }\end{array}$ & Material & $\begin{array}{l}\text { Strength } \\
\text { (ksi) }\end{array}$ \\
\hline & & $10 C-80 / 20$ & $6.7 \pm 1.4$ \\
\hline $80 / 20$ & $5.3 \pm 1.2$ & $20 \mathrm{C}-80 / 20$ & $5.4 \pm 0.9$ \\
\hline \multirow[t]{2}{*}{$90 / 10$} & $5.2 \pm 1.7$ & $10 C-90 / 10$ & $3.4 \pm 1.1$ \\
\hline & \multirow[b]{2}{*}{$7.8 \pm 0.5$} & $20 c-90 / 10$ & $\star \star$ \\
\hline $10 A-80 / 20$ & & \multirow[b]{2}{*}{$10 D-80 / 20$} & \multirow[b]{2}{*}{$\star \star$} \\
\hline $20 A-80 / 20$ & $7.1 \pm 0.4$ & & \\
\hline $10 A-90 / 10$ & $6.5 \pm 4.1$ & \multirow{2}{*}{$\begin{array}{l}20 D-80 / 20 \\
10 D-90 / 10\end{array}$} & \multirow{3}{*}{$\begin{array}{c}\text { ** } \\
4.7 \pm 2.2 \\
\star \star\end{array}$} \\
\hline $20 A-90 / 10$ & $5.2 \pm 0.9$ & & \\
\hline & \multirow[b]{2}{*}{$6.3 \pm 1.1$} & $20 D-90 / 10$ & \\
\hline $10 B-80 / 20$ & & \multirow[b]{2}{*}{$10 \mathrm{E}-80 / 20$} & \multirow[b]{2}{*}{$7.0 \pm 0.3$} \\
\hline $20 B-80 / 20$ & $6.9 \pm 0.4$ & & \\
\hline $10 B-90 / 10$ & $2.8 \pm 0.1$ & $20 E-80 / 20$ & $7.4 \pm 1.2$ \\
\hline \multirow[t]{2}{*}{$20 B-90 / 10$} & \multirow[t]{2}{*}{$\star \star$} & $10 E-90 / 10$ & \multirow{2}{*}{$\begin{array}{l}6.9 \pm 0.3 \\
6.2 \pm 0.3 \\
6\end{array}$} \\
\hline & & $20 E-90 / 10$ & \\
\hline
\end{tabular}

** Acceptable film for measuring tensile properties could not be made. 
Table XII

Percent Strain at $177^{\circ} \mathrm{C}$

\begin{tabular}{|c|c|c|c|}
\hline Material & $\begin{array}{l}\text { Percent } \\
\text { strain at } \\
\text { break }\end{array}$ & Material & $\begin{array}{l}\text { Percent } \\
\text { strain at } \\
\text { break }\end{array}$ \\
\hline & & $10 C-80 / 20$ & $3.3 \pm 1.1$ \\
\hline $80 / 20$ & $2.3 \pm 0.6$ & $20 \mathrm{C}-80 / 20$ & $2.7 \pm 0.7$ \\
\hline \multirow[t]{2}{*}{$90 / 10$} & $2.2 \pm 1.1$ & $10 C-90 / 10$ & $1.3 \pm 0.3$ \\
\hline & \multirow[b]{2}{*}{$3.6 \pm 0.6$} & $20 C-90 / 10$ & * \\
\hline $10 A-80 / 20$ & & \multirow[b]{2}{*}{$10 \mathrm{D}-80 / 20$} & \multirow[b]{2}{*}{$\star \star$} \\
\hline $20 A-80 / 20$ & $2.9 \pm 0.3$ & & \\
\hline $10 A-90 / 10$ & $2.2 \pm 0.5$ & \multirow{2}{*}{$\begin{array}{l}20 D-80 / 20 \\
10 D-90 / 10\end{array}$} & \multirow{3}{*}{$\begin{array}{c}* * \\
1.6 \pm 0.5 \\
* \star\end{array}$} \\
\hline $20 A-90 / 10$ & $1.9 \pm 0.3$ & & \\
\hline & \multirow[b]{2}{*}{$3.1 \pm 0.8$} & $20 D-90 / 10$ & \\
\hline $10 B-80 / 20$ & & \multirow[b]{2}{*}{$10 E-80 / 20$} & \multirow[b]{2}{*}{$2.7 \pm 0.2$} \\
\hline $20 \mathrm{~B}-80 / 20$ & \multirow{2}{*}{$\begin{array}{l}2.6 \pm 0.2 \\
1.2 \pm 0.3\end{array}$} & & \\
\hline $10 B-90 / 10$ & & $20 E-80 / 20$ & $3.1 \pm 0.8$ \\
\hline \multirow[t]{2}{*}{$20 \mathrm{~B}-90 / 10$} & \multirow[t]{2}{*}{ ** } & $10 E-90 / 10$ & \multirow{2}{*}{$\begin{array}{l}2.3 \pm 0.2 \\
2.2 \pm 0.2 \\
\end{array}$} \\
\hline & & $20 E-90 / 10$ & \\
\hline
\end{tabular}

** Acceptable film for measuring tensile properties could not be made. 
Table XIII

Minimum Melt Viscosity and Gel Time

\begin{tabular}{|c|c|c|}
\hline Material & $\begin{array}{c}\text { Minimum Melt } \\
\text { Viscosity (poise) }\end{array}$ & Gel Time (min) \\
\hline $80 / 20$ & 700 & 85 \\
\hline $10 \mathrm{~A}-80 / 20$ & 200 & 88 \\
$20 \mathrm{~A}-80 / 20$ & 70 & 87 \\
\hline & & \\
$10 \mathrm{C}-80 / 20$ & 280 & 78 \\
\hline $10 \mathrm{E}-80 / 20$ & & \\
\hline
\end{tabular}


Table XIV

Ti/Ti Tensile Shear strengths and Processing Conditions

\begin{tabular}{|c|c|c|c|c|}
\hline Material & $\begin{array}{c}\text { Bonding } \\
\text { pressure, } \\
\text { psi }\end{array}$ & $\begin{array}{c}\text { Hold } \\
\text { time, } \\
\text { min }\end{array}$ & $\begin{array}{c}\text { Strength, } \\
\text { psi }\end{array}$ & $\begin{array}{c}\text { Bondline } \\
\text { thickness, } \\
\text { mils }\end{array}$ \\
\hline $20 \mathrm{~A}-80 / 20$ & 15 & 0 & $1450 \pm 150$ & $2.8 \pm 0.2$ \\
& 55 & 0 & $1610 \pm 100$ & $2.7 \pm 0.3$ \\
& 15 & 0 & $1550 \pm 90$ & $3.2 \pm 0.4$ \\
& 15 & 0 & $1280 \pm 90$ & $4.3 \pm 0.2$ \\
& 25 & 0 & $1330 \pm 80$ & $3.4 \pm 0.2$ \\
& 50 & 0 & $1240 \pm 110$ & $3.0 \pm 0.2$ \\
& 15 & 12 & $1400 \pm 60$ & $3.6 \pm 0.5$ \\
\hline $80 / 20$ & 15 & 0 & $940 \pm 60$ & $4.4 \pm 0.1$ \\
& 25 & 0 & $780 \pm 10$ & $3.7 \pm 0.2$ \\
& 50 & 0 & $780 \pm 90$ & $2.6 \pm 0.1$ \\
& 15 & 5 & $1090 \pm 160$ & $4.2 \pm 0.1$ \\
\hline
\end{tabular}


Table XV

$\mathrm{Ti} / \mathrm{Ti}$ Tensile Shear strengths

\begin{tabular}{|c|c|c|c|c|}
\hline \multirow{2}{*}{$\begin{array}{l}\text { Test } \\
\text { Temp }\end{array}$} & \multirow{2}{*}{$\begin{array}{c}48 \mathrm{~h} \\
\text { exposure }\end{array}$} & \multicolumn{3}{|c|}{$\begin{array}{l}\text { Strength, psi } \\
\text { (\% retention) }\end{array}$} \\
\hline & & $20 A-80 / 20$ & $10 A-80 / 20$ & $80 / 20$ \\
\hline $23^{\circ} \mathrm{C}$ & none & $1530 \pm 150$ & $1400 \pm 60$ & $1090 \pm 160$ \\
\hline $177^{\circ} \mathrm{C}$ & none & $\begin{array}{c}1920 \pm 140 \\
(125 \%)\end{array}$ & $\begin{array}{c}2080 \pm 60 \\
(149 \%)\end{array}$ & $\begin{array}{c}1470 \pm 110 \\
(135 \%)\end{array}$ \\
\hline $23^{\circ} \mathrm{C}$ & toluene & $\begin{array}{c}1210 \pm 80 \\
(79 \%)\end{array}$ & $\begin{array}{c}1040 \pm 130 \\
(758)\end{array}$ & $\begin{array}{c}730 \pm 200 \\
(67 \%)\end{array}$ \\
\hline $23^{\circ} \mathrm{C}$ & MEK & $\begin{array}{c}1120 \pm 550 \\
(73 \%)\end{array}$ & $\begin{array}{c}1070 \pm 130 \\
(768)\end{array}$ & $\begin{array}{c}920 \pm 430 \\
(85 \%)\end{array}$ \\
\hline $23^{\circ} \mathrm{C}$ & jet fuel & $\begin{array}{c}1270 \pm 160 \\
(83 \%)\end{array}$ & $\begin{array}{c}1140 \pm 90 \\
(818)\end{array}$ & $\begin{array}{c}690 \pm 430 \\
(64 \%)\end{array}$ \\
\hline $23^{\circ} \mathrm{C}$ & $\begin{array}{l}\text { hydraulic } \\
\text { fluid }\end{array}$ & $\begin{array}{c}1450 \pm 170 \\
(94 \%)\end{array}$ & $\begin{array}{c}1300 \pm 150 \\
(93 \%)\end{array}$ & $\begin{array}{c}850 \pm 270 \\
(78 \%) \\
\end{array}$ \\
\hline
\end{tabular}

${ }^{1}$ Percent of $23^{\circ} \mathrm{C}$ non-exposed values. 

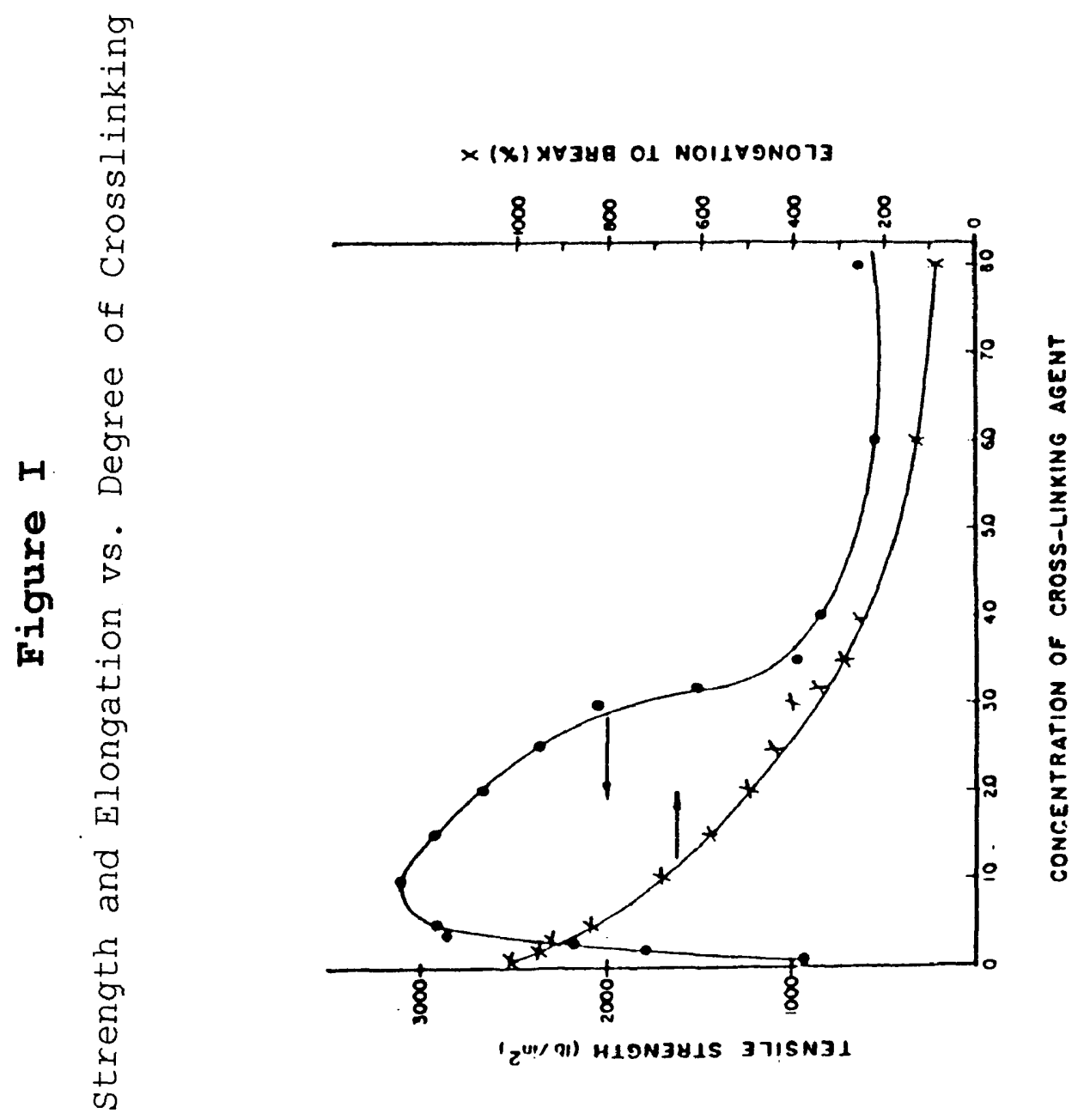


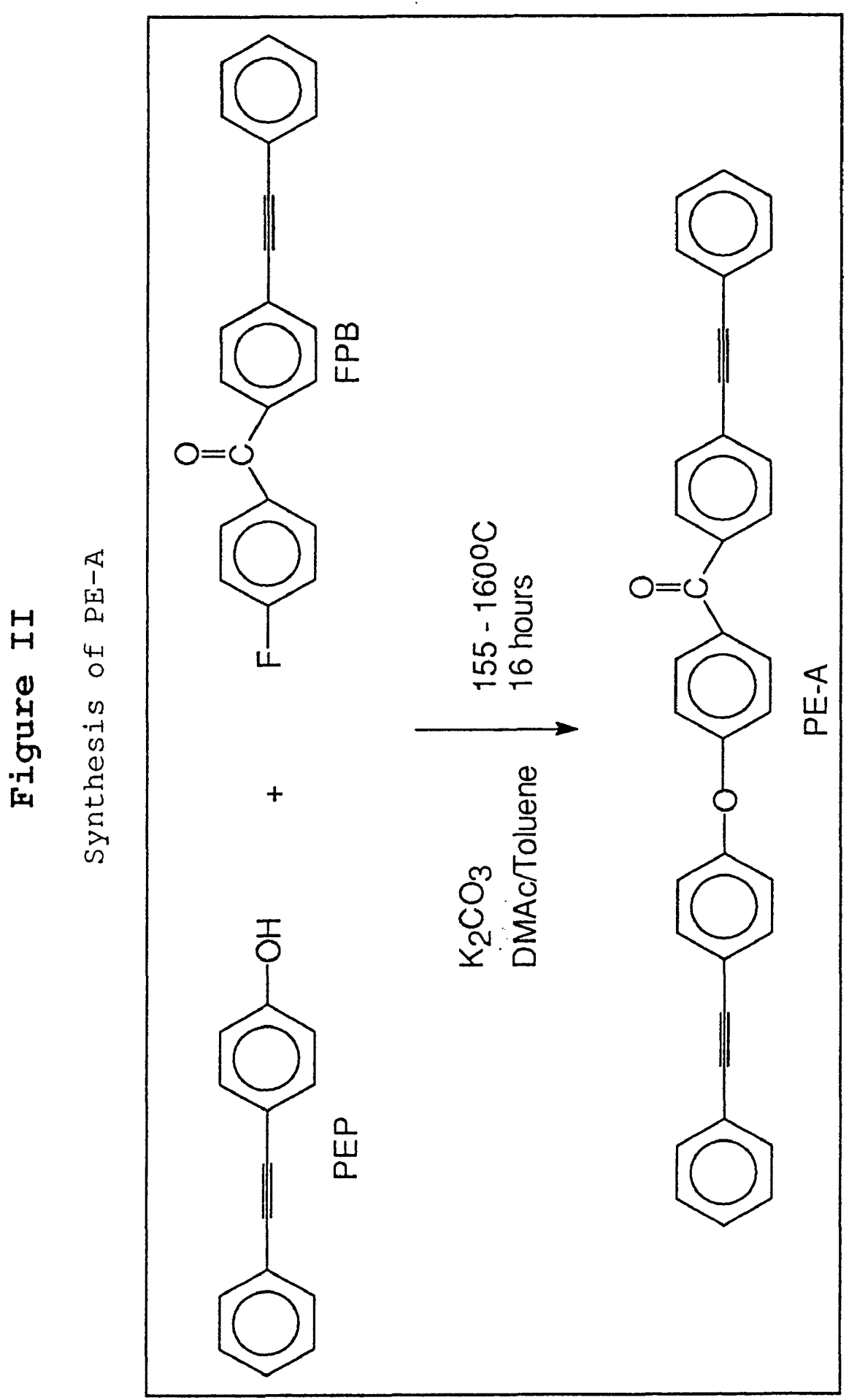




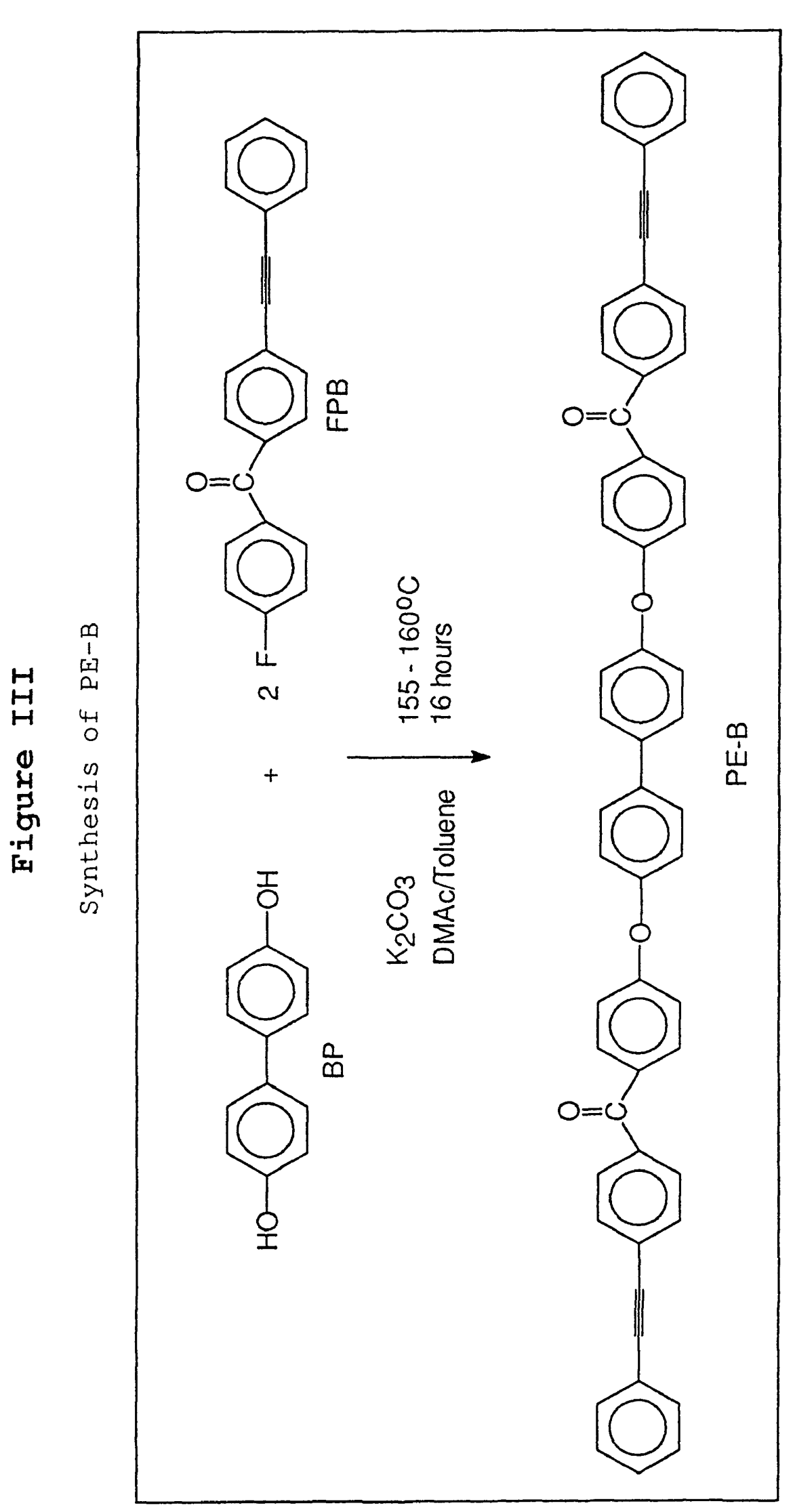




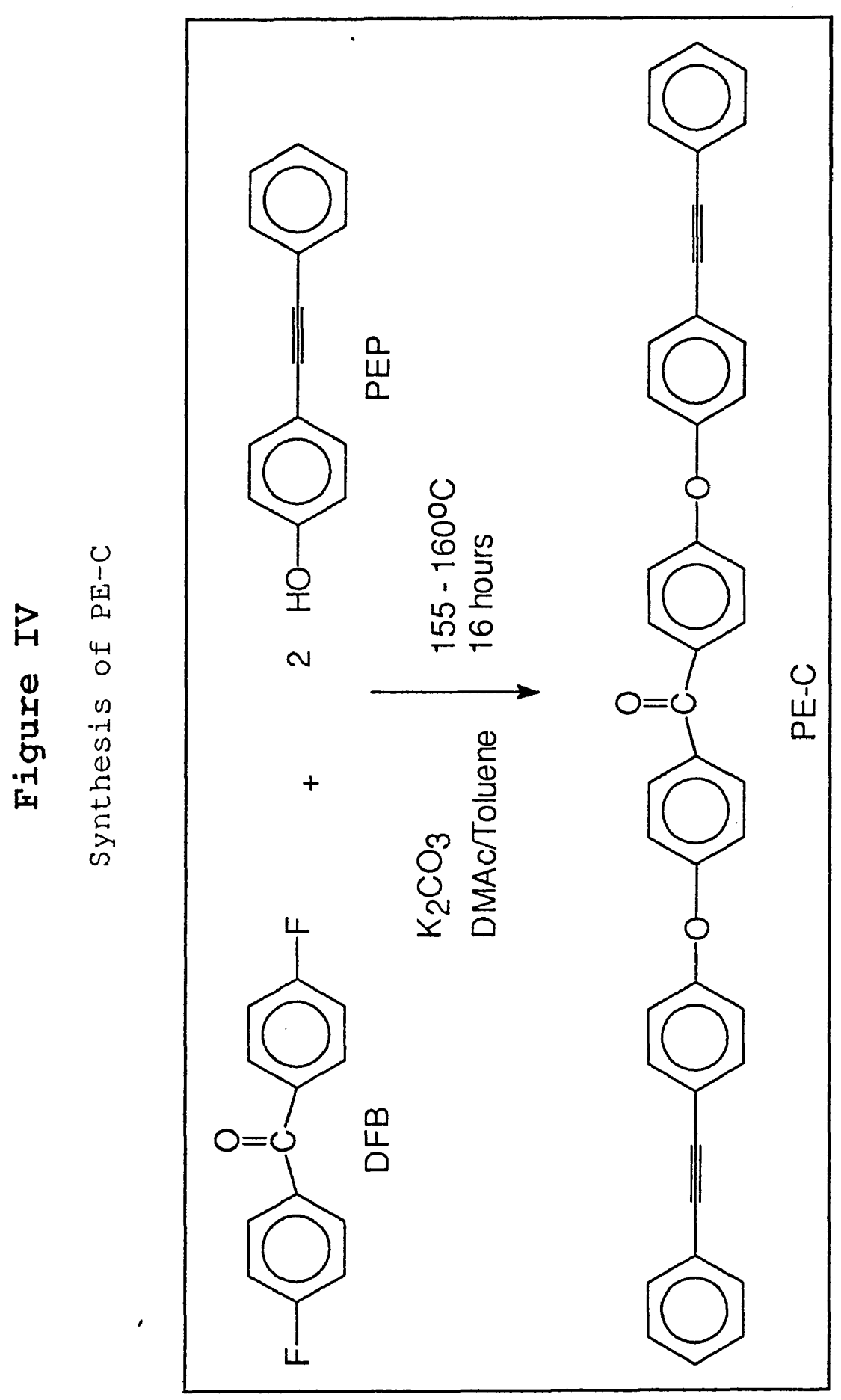




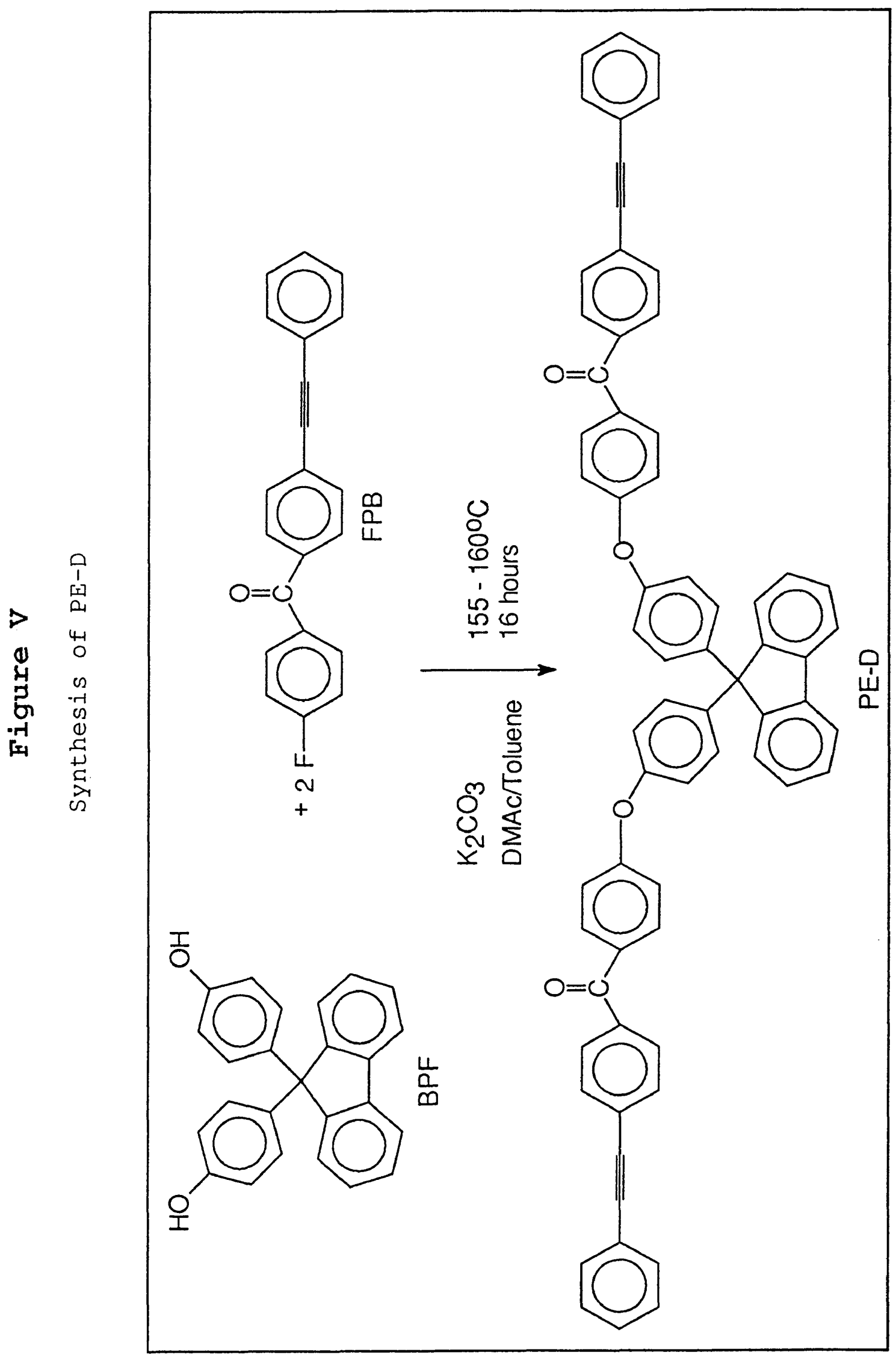




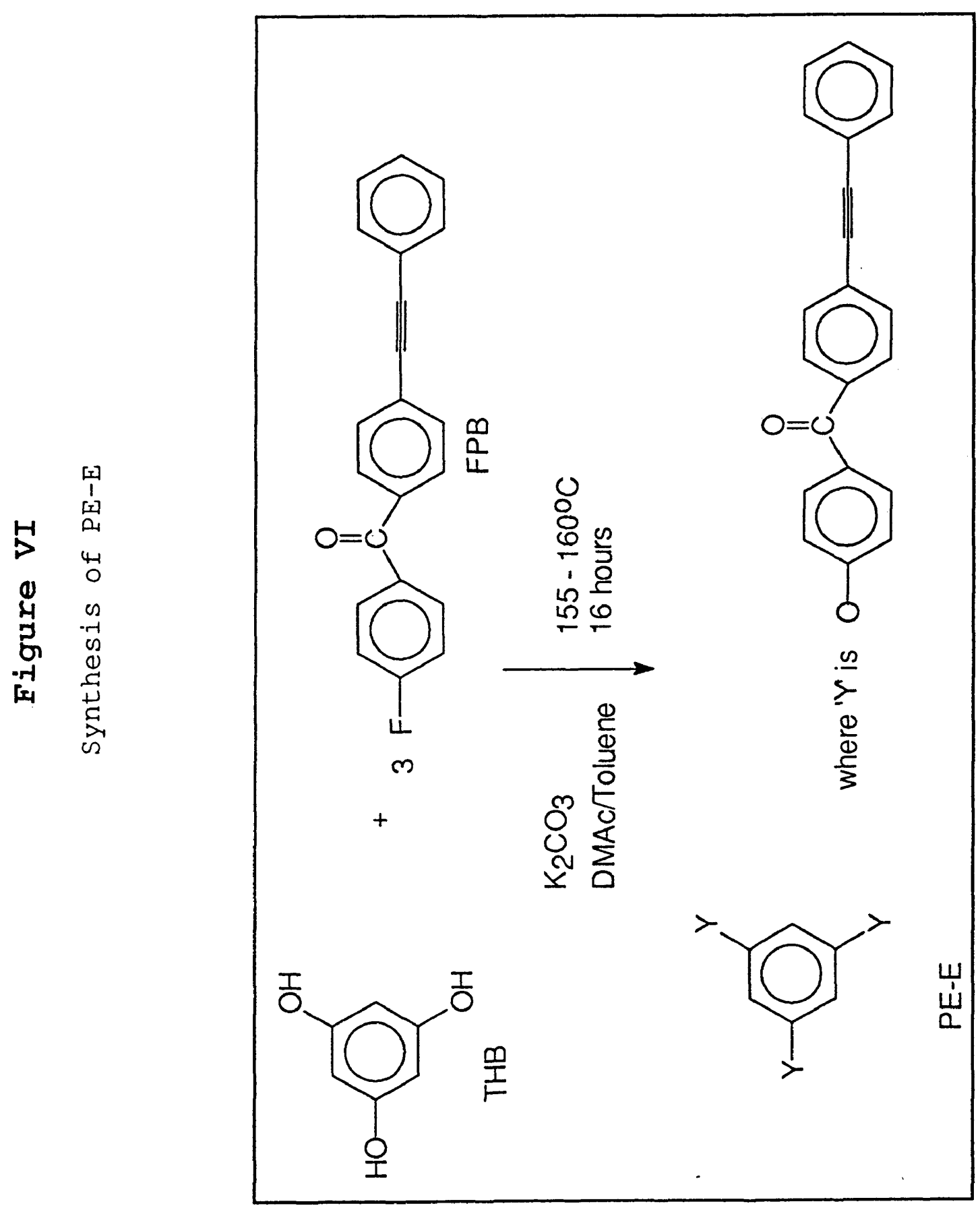




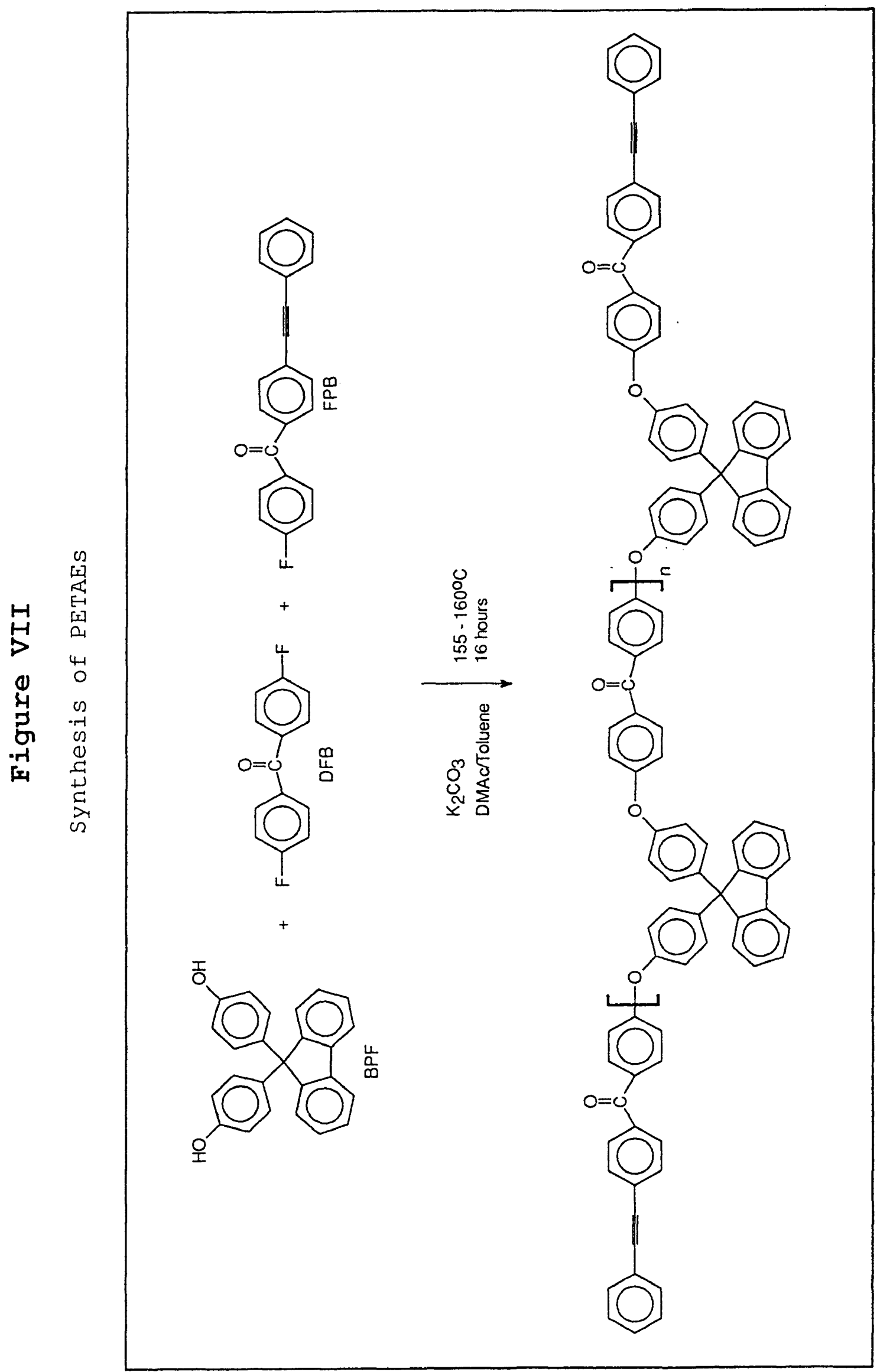




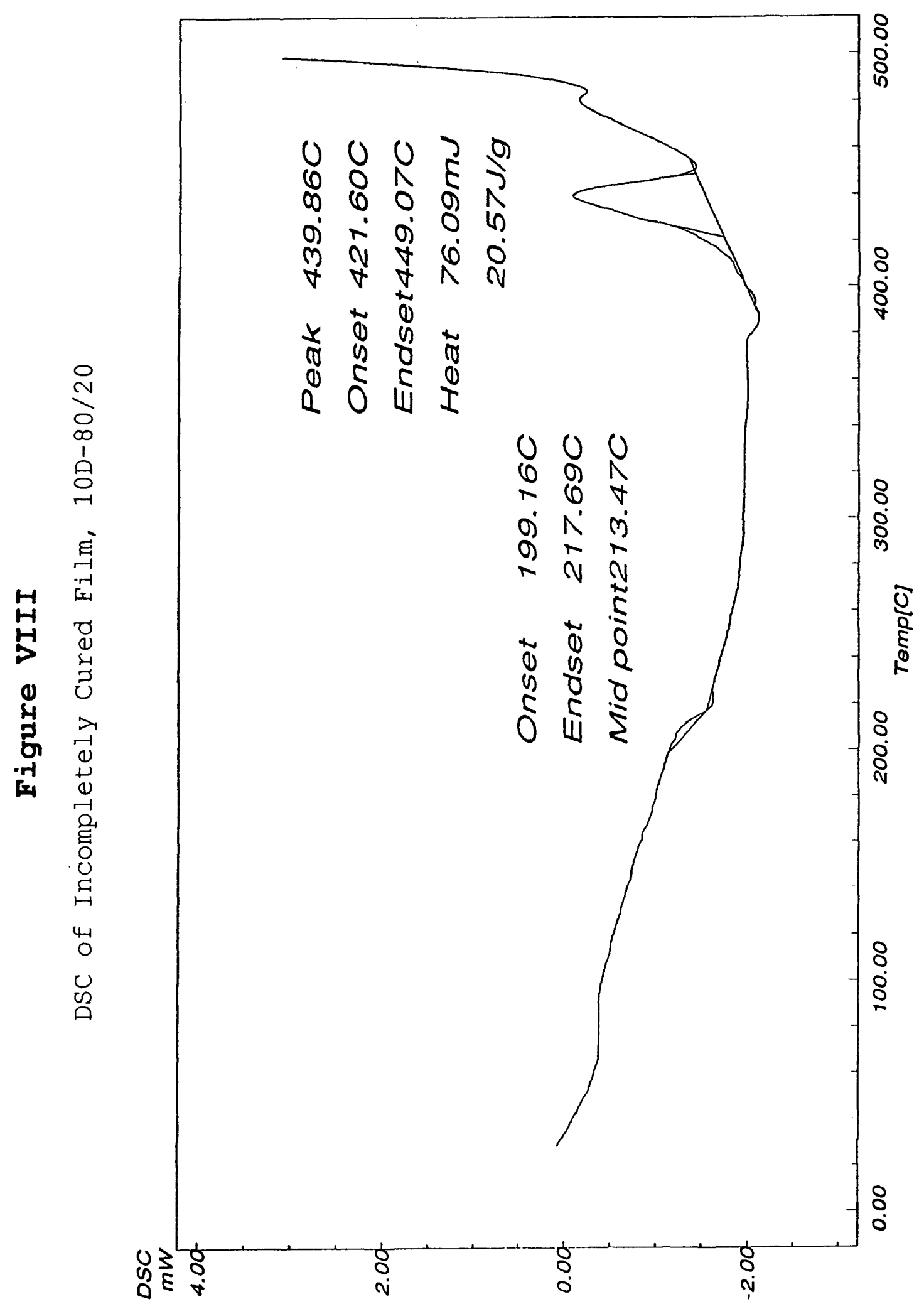




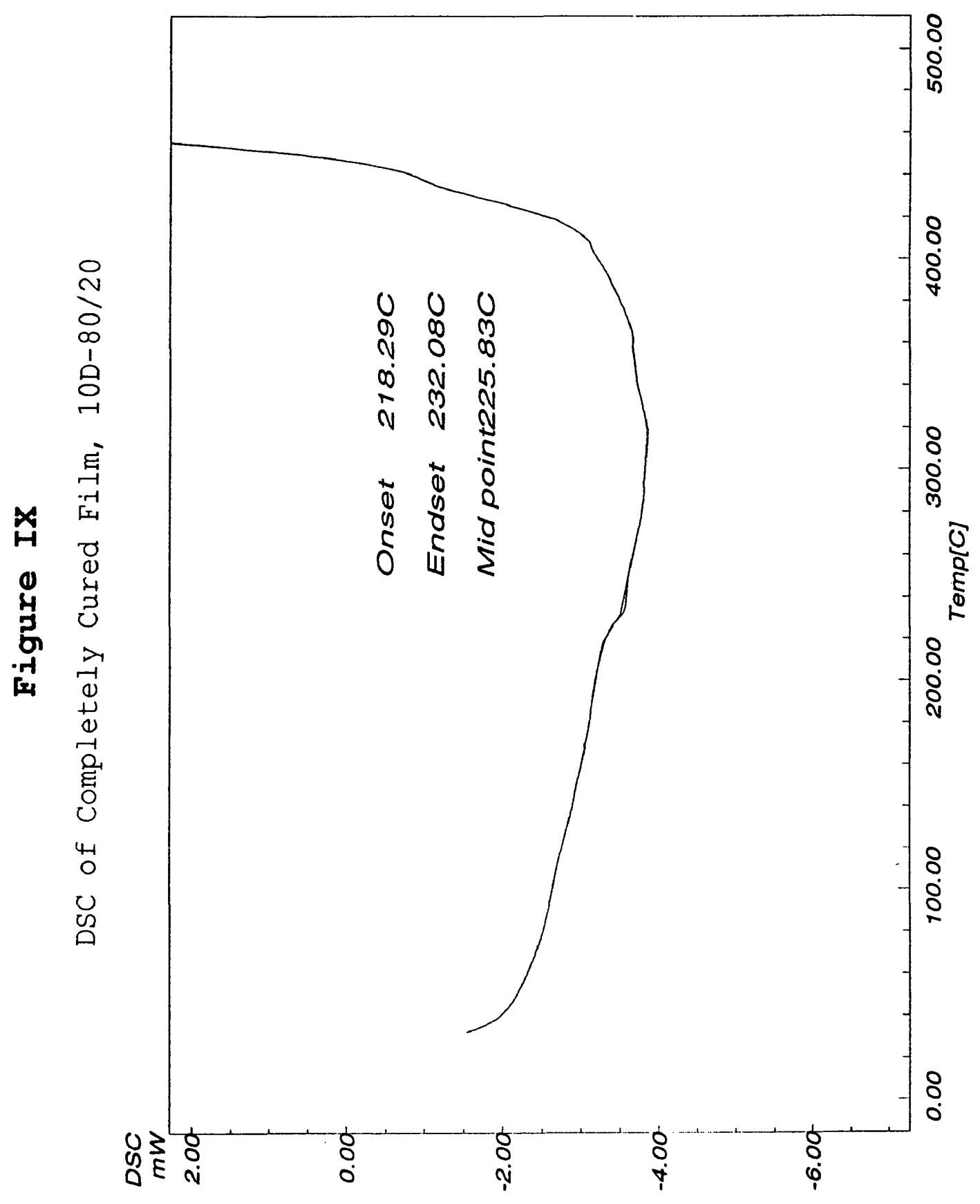




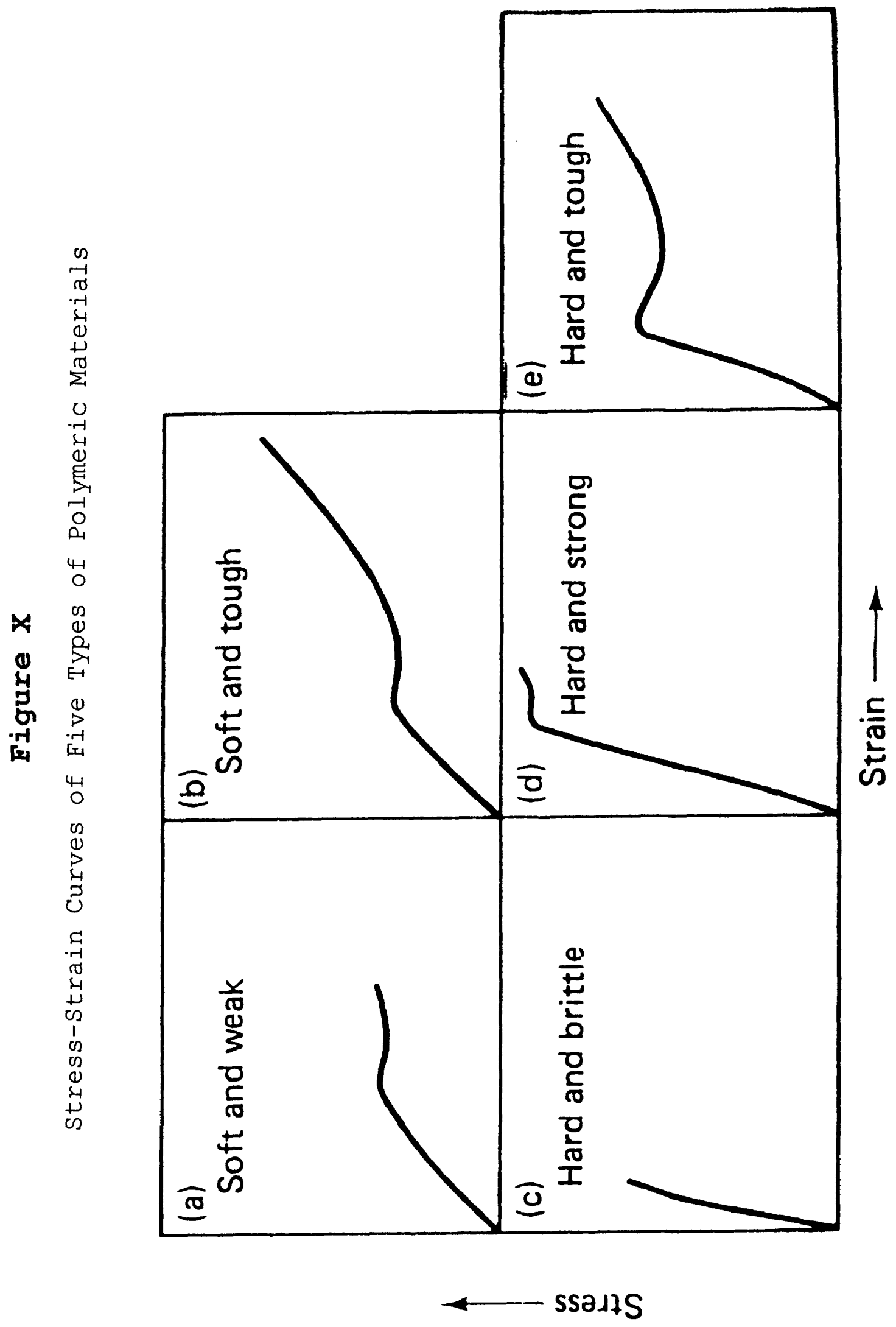




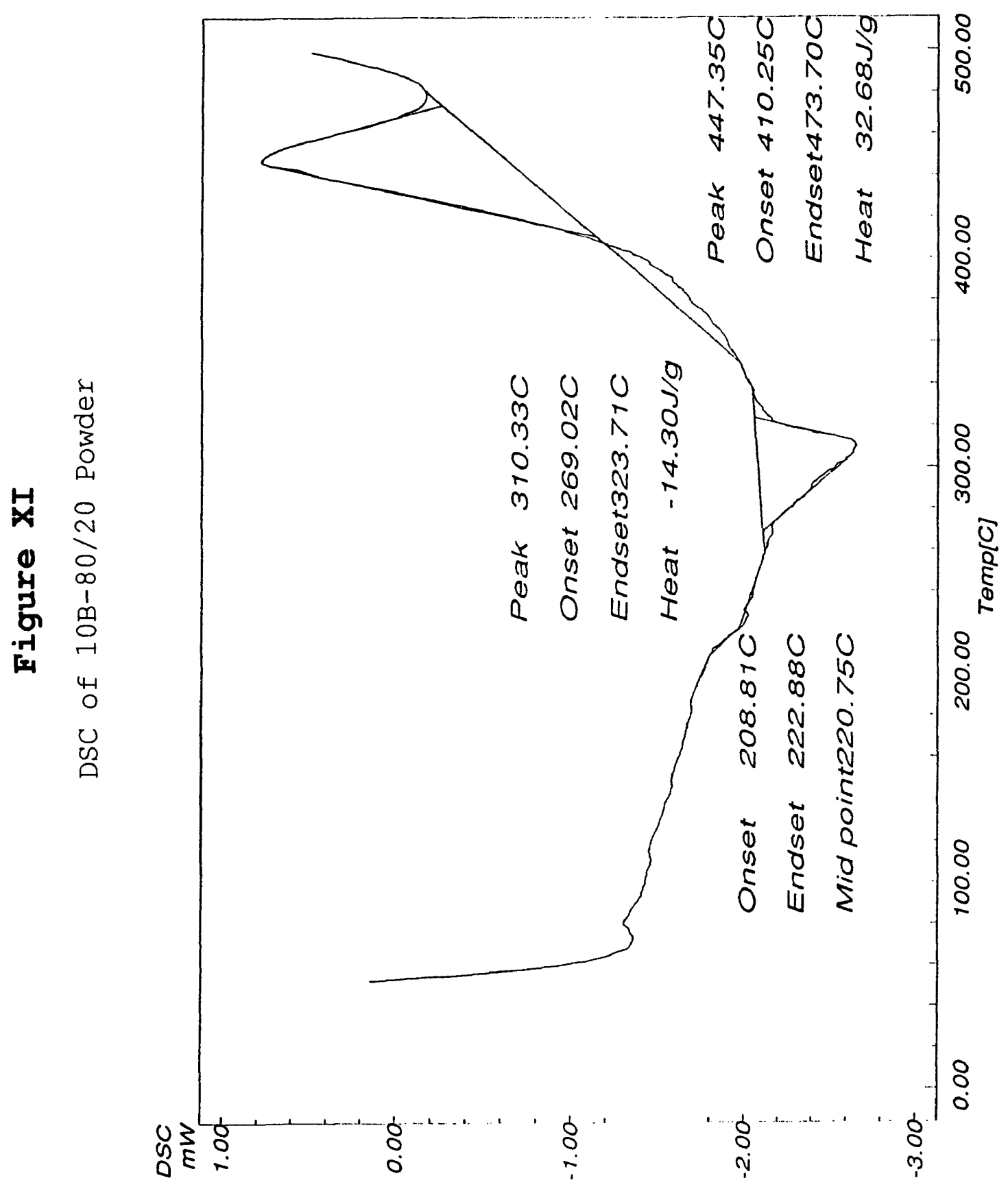




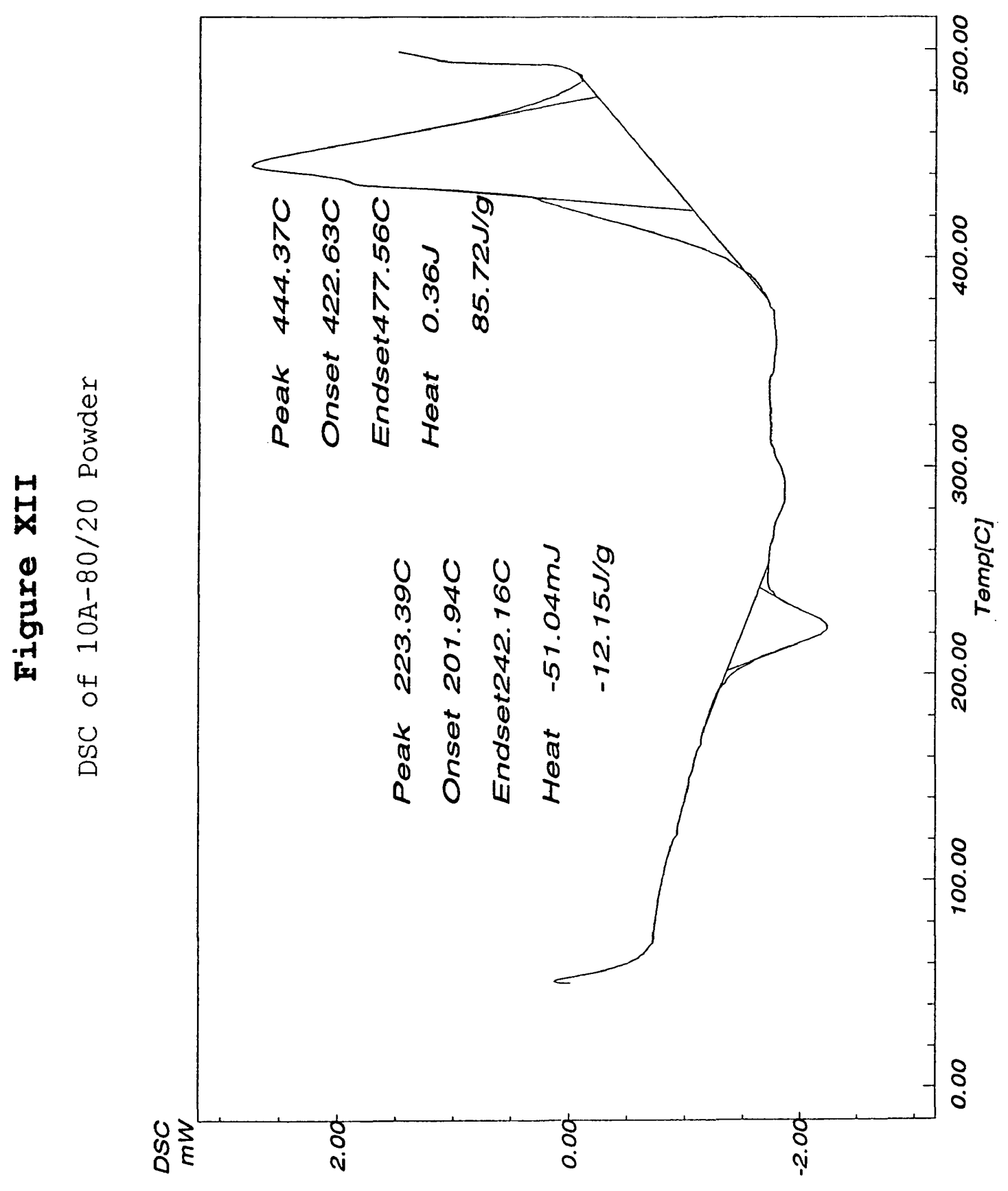




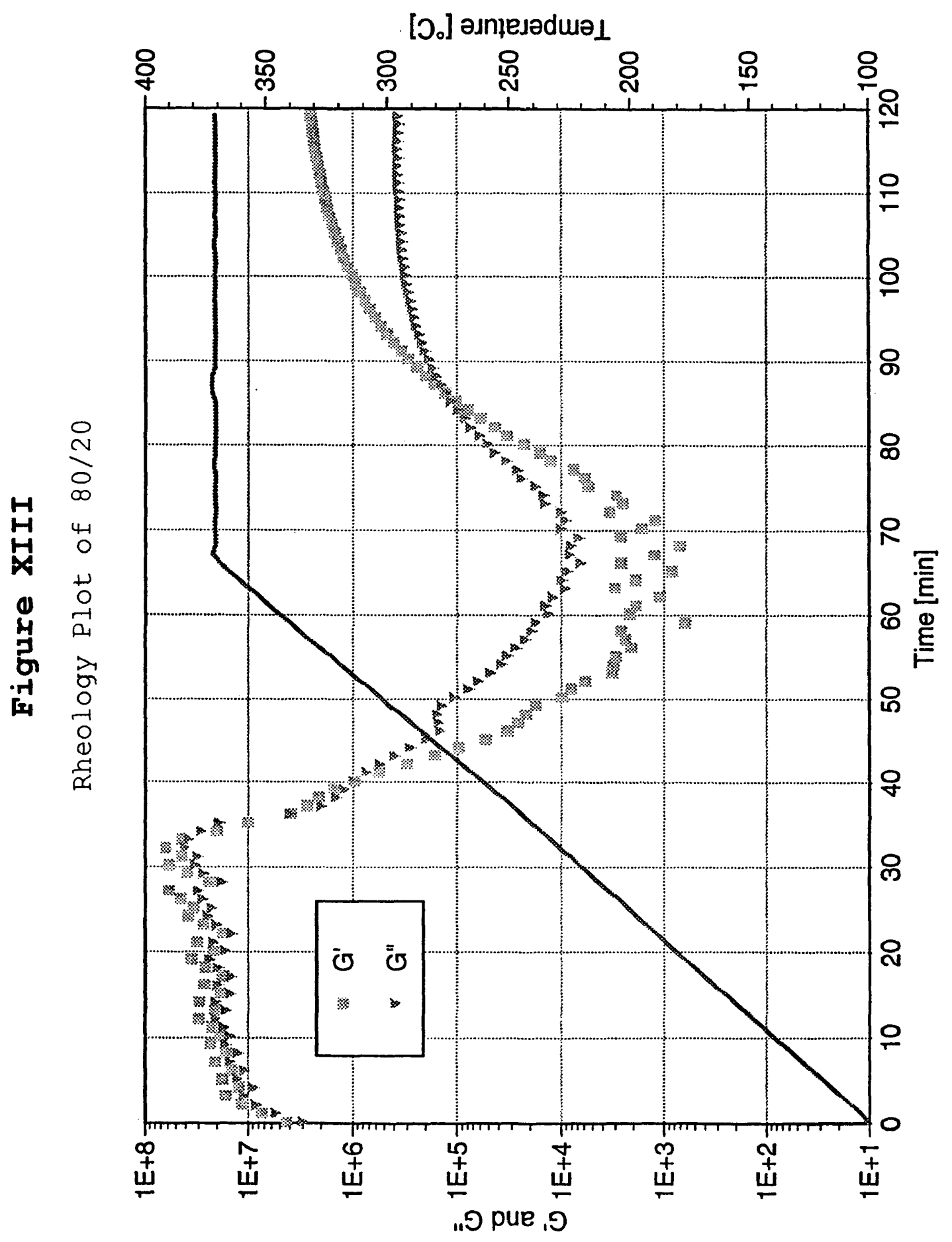




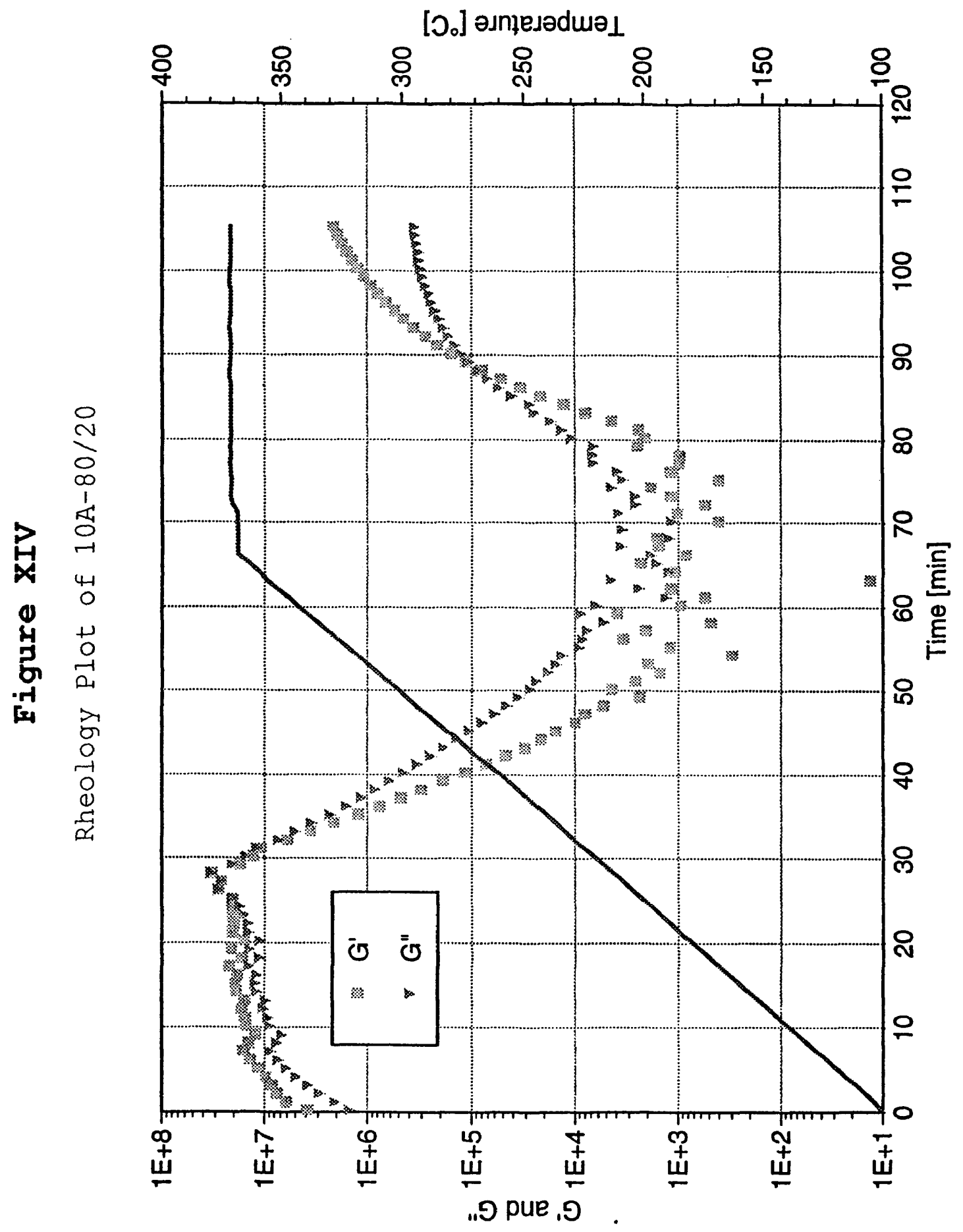




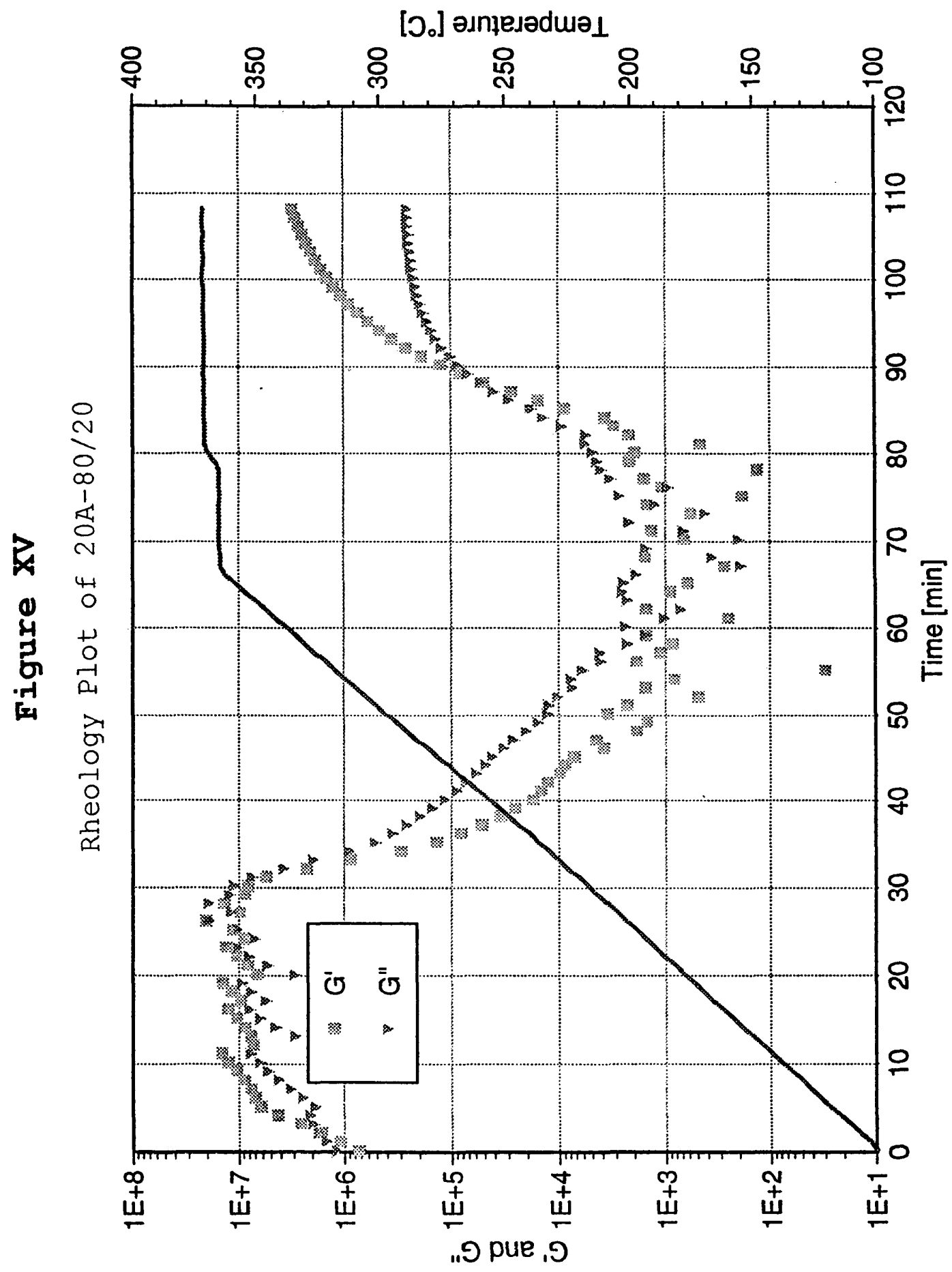




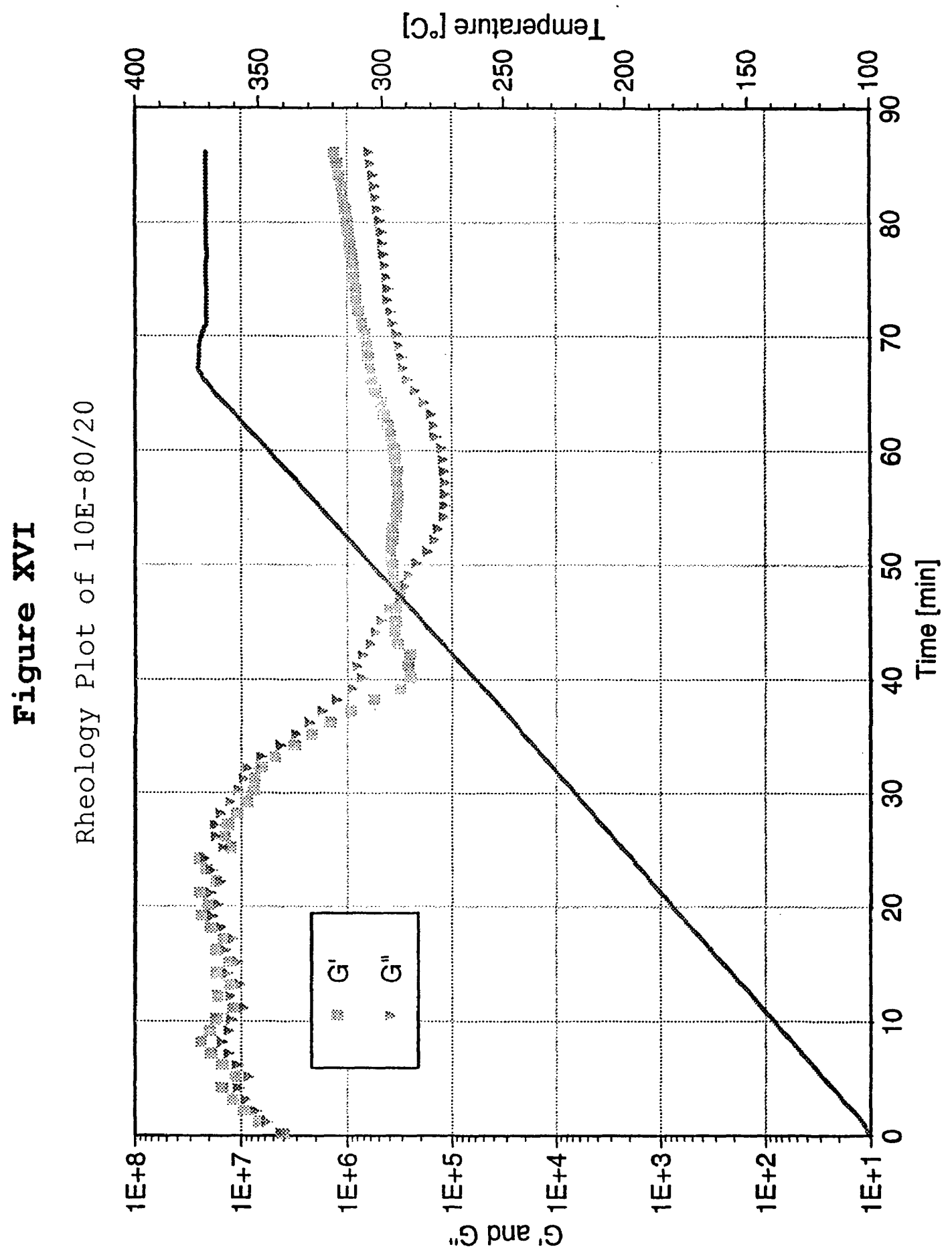




\section{APPENDIX}

Calculation I: Determination of monomer ratio for 6000 g/mol 100/0 oligomer endcapped with FPB (molecular weight based on number of repeat units, excluding endcapper)

$$
\begin{aligned}
& \mathrm{X}_{\mathrm{n}} \quad=\text { degree of polymerization } \\
& x=\text { ratio of } \mathrm{DFB} \text { to } \mathrm{BPF} \\
& \mathrm{MW}_{\text {avg }}=\text { average molecular weight of repeat unit } \\
& \mathrm{MW}_{\mathbf{x}}=\text { molecular weight of } \mathrm{X} \text { (where } \mathrm{x} \text { is DFB, BPF, or FPB) } \\
& \mathrm{MW}_{\mathbf{H}} \text { = molecular weight of hydrogen } \\
& \mathrm{MW}_{\mathrm{F}}=\text { molecular weight of fluorine } \\
& \mathrm{M}_{\text {n(calc) }}=\text { desired number-average molecular weight } \\
& \text { \# mol BPF = desired number of moles of BPF in batch } \\
& \begin{aligned}
\mathrm{MW}_{\mathrm{avg}} & =\left[\mathrm{MW}_{\mathrm{BPF}}+\mathrm{MW}_{\mathrm{DFB}}-2\left(\mathrm{MW}_{\mathrm{H}}+\mathrm{MW}_{\mathrm{F}}\right)\right] / 2 \\
& =[350.421+218.205-2(1.008+18.998)] \mathrm{g} / \mathrm{mol} / 2 \\
& =264.307 \mathrm{~g} / \mathrm{mol} \\
\mathrm{X}_{\mathrm{n}} & =\mathrm{M}_{\mathrm{n} \text { (calc) }} / \mathrm{MW}_{\mathrm{avg}} \\
& =6000 \mathrm{~g} / \mathrm{mol} / 264.307 \mathrm{~g} / \mathrm{mol} \\
& =22.701 \\
\mathrm{x} & =\left(\mathrm{X}_{\mathrm{n}}-1\right) /\left(\mathrm{X}_{\mathrm{n}}+1\right) \\
& =(22.701-1) /(22.701+1) \\
& =0.91562
\end{aligned}
\end{aligned}
$$$$
\text { g BPF needed }=\# \text { mol } \mathrm{BPF} * \mathrm{MW}_{\mathrm{BPF}}
$$$$
=0.1 \mathrm{~mol} * 350.421 \mathrm{~g} / \mathrm{mol}
$$$$
=35.0421 \mathrm{~g}
$$$$
\text { g DFB needed }=\mathrm{MW}_{\mathrm{DFB}}(\# \operatorname{mol} \mathrm{BPF} * r)
$$$$
=218.205 \mathrm{~g} / \mathrm{mol}(0.1 \mathrm{~mol} * 0.91562)
$$$$
=19.9793 \mathrm{~g}
$$$$
\text { \# endgroups }=2[\# \operatorname{mol} B P F(1-r)]
$$$$
=2\left[0.1 \mathrm{~mol}\left(1^{\prime}-0.91562\right)\right]
$$$$
=0.016876
$$

g FPB needed = \# endgroups * $\mathrm{MW}_{\mathrm{FPB}}$$$
=0.016876 * 300.335 \mathrm{~g} / \mathrm{mol}
$$$$
=5.0685 \mathrm{~g}
$$ 
Calculation II: Determination of $90 \%$ confidence limits

$90 \% \mathrm{CL}=90 \%$ confidence limits

$x=$ average of all values

$t=$ statistical parameter (see table below)

$s=$ standard deviation

$N=$ number of replicate measurements

Values of $t$ for $90 \%$ Confidence Limits

\begin{tabular}{|c|c|}
\hline $\begin{array}{c}\text { Degrees of } \\
\text { Freedom }(N-1)\end{array}$ & $t$ \\
\hline 1 & 6.31 \\
\hline 2 & 2.92 \\
\hline 3 & 2.35 \\
\hline 4 & 2.13 \\
\hline 5 & 2.02 \\
\hline
\end{tabular}

$908 \mathrm{CL}=\mathrm{x} \pm \operatorname{ts} /(N)^{1 / 2}$ 


\section{Notes}

1. Haggerty, J. J. Spinoff 1994; National Aeronautics and Space Administration, office of Space Access and Technology, Commercial Development and Technology Transfer Division, $1994 ; \mathrm{p} 10$.

2. Hergenrother, P. M.; Rogalski, M. E. Polym. Prepr. 1992, $33(1), 354$.

3. Mallick, P. M. Fiber Reinforced Composites; Marcel Dekker: New York, 1993; p 404.

4. Johnson, R. N.; Farnham, A. G. ; Clendinning, R. A. ; Hale, W. F.; Merriam, C. N. J. Polym. SCi. (A-1) 1967, 5, 2375 .

5. Hale, W. F.; Farnham, A. G.; Johnson, R. N.; Clendinning, R. A. J. Polym. SCi. (A-1) 1967, 5, 2399.

6. Attwood, T. E.; Dawson, P. C.; Freeman, J. L.; Hoy, L.

R. J.; Rose, J. B.; Staniland, P. A. Polymer 1981, 22, 1096.

7. Hergenrother, P. M.; Jensen, B. J.; Havens, S. J. Polymer 1988, 29(2), 358 .

8. Havens, S. J. J. Polym. Sci., Polym. Chem. Ed. 1984, 22, 3011 .

9. ICI Americas, Inc., Wilmington, DE 19897.

10. Sheppard, C. H.; House, E. E.; Stander, M. Soc. Plast. Ind. Inc. 36th Am. Conf. Prep. Session 1980, 17B, 1.

11. Hergenrother, P. M. Polym. Prepr. Am. Chem. Soc. Div. Org. Coat. Plast. Chem. 1982, 46, 165.

12. Hergenrother, P. M. J. Macromol. Sci.-Rev. Macromol. Chem. 1980, C19(1), 1. 
[Notes to pages $4-8$ ]

13. Hergenrother, P. M. In Encyclopedia of Polymer Science and Engineering, 2nd ed.; John Wiley \& Sons: New York, 1985; Vol. 1, p 61 .

14. Hergenrother, P. M. J. Polym Sci., Polym. Chem. Ed. $1982,20,3131$.

15. Delfort, B.; Lucotte, G.; Cormier, L. J. Polym. Sci., Polym. Chem. Ed. 1990, 28, 2451.

16. Jensen, B. J.; Hergenrother, P. M.; Nwokogu, G. J. Macromol. Sci., Pure Appl. Chem., 1993, A30, 449.

17. Smith, J. G.; Connell, J. W.; Hergenrother, P. M. Polym. Prepr. 1993, 34(1), 875.

18. Bhatnagar, A.; Kozuch, M.; Schaffer, A.; Phulpagar, S.; Mohanty, D. K. Polym. Mat. Sci. Eng. 1995, 72, 361.

19. Jayaraman, S.; Meyer, G.; Moy, T. M.; Srinivasan, R.; McGrath, J. E. Polym. Prepr. 1993, 34(1), 513.

20. Bryant, R. G.; Jensen, B. J.; Hergenrother, P. M. Polym. Prepr. 1992, 33(1), 910.

21. Jensen, B. J.; Bryant, R. G. Polym. Prepr. 1994, 35(1), 513 .

22. Jensen, B. J.; Bryant, R. G.; Hergenrother, P. M. U.S. Patent 5,268,444, 1993 .

23. Jensen, B. J. Polym. Prepr. 1991, 32(3), 222.

24. Nielsen, L. E.; Landel, R. F. Mechanical Properties of Polymers, 2nd ed.; Marcel Dekker: New York, 1994; pp 268269 .

25. Cowie, J. M. G. Polymers: Chemistry and Physics of Modern Materials, 2nd ed.; Chapman and Hall: New York, 1991; p 330 . 
[Notes to pages 9-74]

26. Jayaraman, S.; Srinivasan, R.; MCGrath, J. E. Polym. Prepr. 1993 34(1), 511.

27. Allcock, H. R.; Lampe, F. W. Contemporary Polymer Chemistry, 2nd ed.; Prentice Hall: Englewood Cliffs, NJ, $1990 ; \mathrm{p} 527$. 


\section{Bibliography}

Allcock, H. R.; Lampe, F. W. Contemporary Polymer Chemistry, 2nd ed.; Prentice Hall: Englewood Cliffs, NJ, 1990; p 527 .

Attwood, T. E.; Dawson, P. C.; Freeman, J. L.; Hoy, L. R. J.; Rose, J. B.; Staniland, P. A. Polymer 1981, 22, 1096 .

Bhatnagar, A.; Kozuch, M.; Schaffer, A.; Phulpagar, S.; Mohanty, D. K. Polym. Mat. Sci. Eng. 1995, 72, 361.

Bryant, R. G.; Jensen, B. J.; Hergenrother, P. M. Polym. Prepr. 1992, 33(1), 910.

Cowie, J. M. G. Polymers: Chemistry and Physics of Modern Materials, 2nd ed.; Chapman and Hall: New York, 1991; p 330 .

Delfort, B.; Lucotte, G.; Cormier, L. J. Polym. Sci., Polym. Chem. Ed. 1990, 28, 2451.

Haggerty, J. J. Spinoff 1994; National Aeronautics and Space Administration, Office of Space Access and Technology, Commercial Development and Technology Transfer Division, 1994; p 10 .

Hale, W. F.; Farnham, A. G.; Johnson, R. N.; Clendinning, R. A. J. Polym. Sci. (A-1) 1967, 5, 2399.

Havens, S. J. J. Polym. Sci., Polym. Chem. Ed. 1984, 22, 3011 .

Hergenrother, P. M.; Rogalski, M. E. Polym. Prepr. 1992, $33(1), 354$.

Hergenrother, P. M. Polym. Prepr. Am. Chem. Soc. Div. Org. Coat. Plast. Chem. 1982, 46, 165. 
Hergenrother, P. M. J. Macromol. Sci.-Rev. Macromol. Chem. $1980, C 19(1), 1$.

Hergenrother, P. M. In Encyclopedia of Polymer Science and Engineering, 2nd ed.; John Wiley \& Sons: New York, 1985; Vol. 1, p 61.

Hergenrother, P. M. J. Polym Sci., Polym. Chem. Ed. 1982, 20,3131 .

Hergenrother, P. M.; Jensen, B. J.; Havens, S. J. Polymer $1988,29(2), 358$.

ICI Americas, Inc., Wilmington, DE 19897.

Jayaraman, S.; Srinivasan, R.; McGrath, J. E. Polym. Prepr. $1993,34(1), 511$.

Jayaraman, S.; Meyer, G.; Moy, T. M.; Srinivasan, R.; McGrath, J. E. Polym. Prepr. 1993, 34(1), 513.

Jensen, B. J.; Hergenrother, P. M.; Nwokogu, G. J. Macromol. Sci., Pure Appl. Chem., 1993, A30, 449.

Jensen, B. J. Polym. Prepr. 1991, 32(3), 222.

Jensen, B. J.; Bryant, R. G. Polym. Prepr. 1994, 35(1), 513.

Jensen, B. J.; Bryant, R. G.; Hergenrother, P. M. U.S. Patent 5,268,444, 1993 .

Johnson, R. N.; Farnham, A. G.; Clendinning, R. A.; Hale, W. F.; Merriam, C. N. J. Polym. Sci. (A-1) 1967, 5, 2375.

Mallick, P. M. Fiber Reinforced Composites; Marcel Dekker: New York, 1993; p 404.

Nielsen, L. E.; Landel, R. F. Mechanical Properties of Polymers, 2nd ed.; Marcel Dekker: New York, 1994; pp 268-269.

Sheppard, C. H.; House, E. E.; Stander, M. SoC. Plast. Ind. Inc. 36th Am. Conf. Prep. Session 1980, 17B, 1.

Smith, J. G.; Connell, J. W.; Hergenrother, P. M. Polym. Prepr. 1993, 34(1), 875. 


\title{
VITA
}

\author{
Rachel Louise Knudsen
}

Born in Fredericksburg, VA, February 14, 1971. Graduated from Stafford High School in that city, June 1989. Langley Aerospace Research Summer Scholars Program, NASA Langley Research Center, Hampton, Va, Summer 1993. B.S., Chemistry, Virginia Polytechnic Institute and State University, December, 1993. M.A. candidate, Applied Science, College of William and Mary in Virginia, 1993-95. 